\title{
High-Power ZBLAN Glass Fiber Lasers: Review and Prospect
}

\author{
Xiushan Zhu and N. Peyghambarian \\ College of Optical Sciences, University of Arizona, 1630 East University Boulevard, Tucson, AR 85721, USA \\ Correspondence should be addressed to Xiushan Zhu, xszhu@email.arizona.edu
}

Received 15 October 2009; Accepted 7 January 2010

Academic Editor: Iyad Dajani

Copyright ( $2010 \mathrm{X}$. Zhu and N. Peyghambarian. This is an open access article distributed under the Creative Commons Attribution License, which permits unrestricted use, distribution, and reproduction in any medium, provided the original work is properly cited.

\begin{abstract}
ZBLAN $\left(\mathrm{ZrF}_{4}-\mathrm{BaF}_{2}-\mathrm{LaF}_{3}-\mathrm{AlF}_{3}-\mathrm{NaF}\right)$, considered as the most stable heavy metal fluoride glass and the excellent host for rare-earth ions, has been extensively used for efficient and compact ultraviolet, visible, and infrared fiber lasers due to its low intrinsic loss, wide transparency window, and small phonon energy. In this paper, the historical progress and the properties of fluoride glasses and the fabrication of ZBLAN fibers are briefly described. Advances of infrared, upconversion, and supercontinuum ZBLAN fiber lasers are addressed in detail. Finally, constraints on the power scaling of ZBLAN fiber lasers are analyzed and discussed. ZBLAN fiber lasers are showing promise of generating high-power emissions covering from ultraviolet to mid-infrared considering the recent advances in newly designed optical fibers, beam-shaped high-power pump diodes, beam combining techniques, and heatdissipating technology.
\end{abstract}

\section{Introduction}

Since the first demonstration of laser emission from a ruby crystal (chromium-doped corundum) in 1960 [1], hundreds of crystals and glasses doped with rare-earth ions have been fabricated and utilized in solid-state lasers to generate coherent emissions at different wavelengths. In contrast to crystals, glasses do not only have broad laser transitions which are essential conditions for wavelength tuning and ultrashort pulses generation but also have broad absorption spectra that relieve the wavelength tolerance for the pump sources. Most importantly, single-mode optical fibers, as the most flexible and compact gain media for highefficiency and excellent beam-quality laser generation, are mostly drawn from glasses. Although crystalline fibers can be drawn using techniques of edge-defined film-fed growth [2], micropulling-down [3], and laser heated pedestal growth [4], their cores cannot be precisely controlled to be small enough to ensure exclusive single-transverse-mode guiding and their lengths are also technically limited. To date, silicate, phosphate, fluoride, and chalcogenide glasses can be drawn into single-mode fibers. A variety of lasers have also been demonstrated in these glass fibers. The spectral range of glass fiber lasers can cover from ultraviolet (UV) to mid- infrared and the output power of a single-element fiber laser can be up to 6 kilo-watts [5]. In contrast to other lasers, the attractive features of fiber lasers include outstanding heat-dissipating capability, excellent beam quality, high optical conversion efficiency, simplicity and compactness, high single-pass gain, low laser threshold, and broad gain bandwidth.

Silicate glasses are outstanding hosts for rare-earth ions and most of recent fiber lasers are constructed with silica fibers due to their low loss, high tenability, and strong strength. Phosphate glass as the host for the fiber lasers has a high solubility that enables extremely high doping level of rare-earth ions (up to $20 \mathrm{wt} \%$ ) and now is mostly used for high-gain fibers. Very high-gain per unit fiber length $(\sim 5 \mathrm{~dB} / \mathrm{cm})$ can be obtained and watt-level outputs have been delivered from short-length $(<10 \mathrm{~cm})$ fiber cavities that support oscillation with single longitude mode [6, 7]. Fluoride and chalcogenide glasses have drawn much attention because they are found to have low phonon energy and mid-infrared transparency. These glasses are excellent candidates for fiber lasers in visible and mid-infrared regions where emissions are hard to be obtained from silicate and phosphate fibers. Comparing to chalcogenide fibers, fluoride fibers have been studied for lasing actions with more 
significant efforts due to their high allowable doping levels (up to $10 \mathrm{~mol} \%$ ), relatively high strength, high stability, and low background loss $(<0.05 \mathrm{~dB} / \mathrm{m})$. Chalcogenide fibers are generally investigated for nonlinear wavelength transfer due to their high nonlinearity $[8,9]$. Though there are some studies on rare-earth-doped chalcogenide fiber lasers and amplifiers [10-13], their efficiencies and output powers are relatively low due to the low available rare-earth doping level $(\sim 0.1 \mathrm{~mol} \%)$, the large background loss $(0.5-1 \mathrm{~dB} / \mathrm{m})$, and the fragility of chalcogenide glasses. Significant longterm efforts are needed before the realization of high output power chalcogenide fiber lasers for practical applications. In contrast to chalcogenide fiber lasers, a plenty of fluoride glass fiber lasers have been reported in the past two decades and ten-watt-level output powers have already been demonstrated [14-16]. So far there are only a few reviews on the progress of fluoride fiber lasers and they are dated before 1995 [17, 18]. In this paper we give an overview of fluoride glass fiber lasers and show their promise for generating highpower emissions covering from UV to mid-infrared.

The paper is organized as follows. Progresses and properties of fluoride glasses and fabrication of fluoride fibers are briefly described in Section 2. Reviews on mid-infrared lasers, upconversion UV and visible lasers, and supercontinuum generation are presented in Section 3. Analyses and discussions on power scaling of fluoride fiber lasers are completed with calculations in Section 4. Summary is given at the end of this paper.

\section{Fluoride Glass Synthesis and ZBLAN Fiber Fabrication}

Since detailed descriptions of heavy metal fluoride (HMF) glasses and complete investigations of their properties can be found in the literature [19-28], we only briefly discuss here the synthesis of fluoride glasses and the fabrication of ZBLAN $\left(\mathrm{ZrF}_{4}-\mathrm{BaF}_{2}-\mathrm{LaF}_{3}-\mathrm{AlF}_{3}-\mathrm{NaF}\right)$ fibers. Basic properties of ZBLAN glass are also summarized in this section as a preparation for the discussion in Section 4.

2.1. Fluoride Glass Synthesis. In the history of science and technology, unexpected outcome of an experiment usually leads to a fantastic discovery. Poulain's discovery of the fluorozirconate glasses was entirely a "surprise". In 1974, he was working on the synthesis and characterization of $\mathrm{ZrF}_{4}$-containing crystalline compounds doped with rare earths in the laboratory of Jacques Lucas at the University of Rennes. When $\mathrm{NaF}$ was added to fill the voids in the crystal structure of a $\mathrm{ZrF}_{4}-\mathrm{BaF}_{2}$ phase, the mixture of $\mathrm{ZrF}_{4}-\mathrm{BaF}_{2}-\mathrm{NaF}-\mathrm{NdF}_{3}$ system was unexpectedly a glass. One year later, the first description of "fluorozirconate" glasses was produced with additional vitreous compositions [29]. ZBLAN glass, referring to a mixture of $\mathrm{ZrF}_{4}-\mathrm{BaF}_{2}-\mathrm{LaF}_{3}-\mathrm{AlF}_{3}-$ $\mathrm{NaF}$ with a molar composition of $53 \% \mathrm{ZrF}_{4}, 20 \% \mathrm{BaF}_{2}, 4 \%$ $\mathrm{LaF}_{3}, 3 \% \mathrm{AlF}_{3}$, and $20 \% \mathrm{NaF}$, considered as the most stable glass practical for optical fiber applications, was reported first by Ohsawa et al. of the Furukawa Electic Co. in 1981 [30]. Although Poulain's $\mathrm{ZrF}_{4}-\mathrm{BaF}_{2}-\mathrm{NaF}$ ternary system was not a very stable glass, it represents 90-95 percent of the most common standard composition of ZBLAN glass.

Compared to silica glasses, it is more complicated to make fluoride glasses. This is due to the fact that to achieve high quality fluoride glasses, not only extremely pure starting materials with infrared-absorbing impurities below $1 \mathrm{ppb}$ are needed but also absolute absence of water and prevention of contamination are required at all synthesis stages. Ammonium hydrogen difluoride $\left(\mathrm{NH}_{4} \mathrm{~F} \cdot \mathrm{HF}\right)$ is extensively used as a fluorinating agent for conversion of metal oxides to fluorides and also as an additive to fluoride mixtures to provide a fluorinating atmosphere during meltdown. The first step of manufacturing fluoride glass is to synthesize and purify the metal fluorides as precursors. After weighing and mixing the various components, the main work consists in melting the batch and pouring the melt onto a hot mold. Generally, any liquid is likely to form a glass if it is cooled fast enough. However, the HMF glasses are particularly prone to crystallization because of the closeness of their glass transition temperature to their melting points and their low melt viscosities. Therefore, most fluoride glasses must be cooled at rates in excess of $0.1 \mathrm{~K} / \mathrm{s}$ to completely avoid the occurrence of crystallization. After synthesis, fluoride glasses need to be completely annealed before they are exposed in common environments.

It should be noted that the basic ZBLAN composition is frequently modified to change the glass properties. For instance, viscosity and refractive index may be modified by the addition of small quantities of $\mathrm{ZnF}_{2}, \mathrm{CaF}_{2}$, and $\mathrm{PbF}_{2}$; infrared edge can be shifted from $6-7 \mu \mathrm{m}$ to $7-8 \mu \mathrm{m}$ and 8 $9 \mu \mathrm{m}$ by substituting $\mathrm{ZrF}_{4}$ by $\mathrm{HfF}_{4}$ and $\mathrm{ThF}_{4}$, respectively; $\mathrm{AlF}_{3}$ may be substituted by $\mathrm{GaF}_{3}$ or $\mathrm{InF}_{3}$ and $\mathrm{NaF}$ by LiF to control the glass stability.

2.2. Properties of ZBLAN Glass. Because of their broad transmission window, low optical dispersion, low refractive index, ease of machining and polishing, and small thermal dependence of the optical properties, HMF glasses have drawn significant attention since Poulain's unexpected discovery. ZBLAN glass as the most stable HMF glass was extensively investigated for their ease of fiber drawing. In this subsection, properties of ZBLAN glass are summarized with a comparison to those of silica glass.

Because the fluoride ion is singly charged, bond strengths are lower in ZBLAN glass than in silica glass. The weaker bonding leads to greater infrared transparency and higher chemical reactivity. Simply speaking, infrared edge of ZBLAN glass is much longer than that of silica glass, but stability and hardness of ZBLAN glass is much lower than those of silica glass. This suggests that ZBLAN glass will be susceptible to handling damage and ZBLAN fibers need special coating to improve their strength for practical applications.

Optical glasses, especially those used for fiber fabrication, should have a background loss as small as possible due to the relative long length of optical fibers (from meters to kilometers). Attenuation of light propagating in an optical glass comes from intrinsic and extrinsic processes. 
TABLE 1: Comparison of basic properties between silica and ZBLAN glasses [20-28].

\begin{tabular}{lcc}
\hline Glass property & Silica & ZBLAN \\
\hline Approximate transmission range $(1 \mathrm{~mm}$ thickness, $T>10 \%)(\mu \mathrm{m})$ & $0.16-4.0$ & 1100 \\
Maximum phonon energy $\left(\mathrm{cm}^{-1}\right)$ & 1175 & $0.22-8.0$ \\
Transition temperature $\left({ }^{\circ} \mathrm{C}\right)$ & 0.179 & 260 \\
Specific heat $(\mathrm{J} / \mathrm{g} \cdot \mathrm{K}))$ & 1.38 & 0.151 \\
Thermal conductivity, $\mathrm{W} /(\mathrm{m} \cdot \mathrm{K})$ & 0.55 & 0.628 \\
Expansion coefficient $\left(10^{-6} / \mathrm{K}\right)$ & 2.20 \\
Density $\left(\mathrm{g} / \mathrm{cm}^{3}\right)$ & 600 \\
Knoop hardness $\left(\mathrm{kg} / \mathrm{mm}^{2}\right)$ & 0.72 \\
Fracture toughness $\left(\mathrm{MPam}{ }^{1 / 2}\right)$ & 0.17 \\
Poisson's ratio & 70 \\
Young's modulus $(\mathrm{Gpa})$ & 31.2 \\
Shear's modulus $(\mathrm{Gpa})$ & 36.7 \\
Bulk's modulus $(\mathrm{Gpa})$ & 17.2 \\
Refractive index $(@ 0.589$ um $)$ & 1.458 \\
Abbe number & 6.33 \\
Zero material dispersion wavelength $(\mu \mathrm{m})$ & 68 \\
Nonlinear index $\left(10^{-13}\right.$ esu $)$ & 1.3 \\
Thermo-optic coefficient $\left(10^{-6} / \mathrm{K}\right)$ & 0.32 \\
\hline
\end{tabular}

Intrinsic processes include band-gap absorption, Rayleigh scattering, and multiphonon absorption. Because band-gap absorption and Rayleigh scattering are only significant at short wavelengths, lower intrinsic loss can be obtained by shifting infrared edge of multiponon absorption to longer wavelengths. It is straightforward that materials with the lower bond strength and the higher reduced mass would be expected to have fundamental absorptions at longer wavelengths. Both these criteria are met in ZBLAN glass since fluoride anion is only single charged and the average cation mass is typically 90 . Consequently, the minimum loss coefficient for ZBLAN glass is predicted as low as $0.01 \mathrm{~dB} / \mathrm{km}$ at $2.5 \mu \mathrm{m}$ [24], which is much less than silica's $0.2 \mathrm{~dB} / \mathrm{km}$ at $1.5 \mu \mathrm{m}$. This stimulated a tremendous interest on ZBLAN fiber as an alternative fiber for long-haul optical communications in 1980s. The attenuation coefficient of less than $1 \mathrm{~dB} / \mathrm{km}$ has been demonstrated on ZBLAN fibers fabricated in labs [31]. However, the typical background loss of commercial ZBLAN fibers $(10-100 \mathrm{~dB} / \mathrm{km})$ is still much larger than that of commercial silica fibers $(0.2 \mathrm{~dB} / \mathrm{km})$ due to the extrinsic scattering and absorption that are relatively difficult to control in the fabrication process. Extrinsic absorption originates from impurities such as transition metals $(\mathrm{Fe}, \mathrm{Cu}, \mathrm{Co}, \mathrm{Ni})$, rare earths $(\mathrm{Nd}, \mathrm{Tb}, \mathrm{Er}), \mathrm{OH}$ and $\mathrm{H}_{2} \mathrm{O}$, and other molecular species $\left(\mathrm{CO}, \mathrm{CO}_{2}, \mathrm{NH}_{4}^{+}\right)$ and extrinsic scattering is resulted from bubbles, crystals, inclusions, and geometrical defects impurities.

Physical properties of ZBLAN glass and silica glass are listed in Table 1. Obviously, the mechanical, optical, and thermal resistibility of ZBLAN glass is much lower than that of silica glass. As a result, output levels of ZBLAN fiber lasers would be much lower than those of silica fiber lasers.
2.3. ZBLAN Fiber Fabrication. Since ZBLAN glass can be cooled more slowly than $1 \mathrm{~K} / \mathrm{s}$ without noticeable homogeneous nucleation, it has been considered to be as the most stable HMF glass and the most resistant to crystallization under optical fiber preform-making and drawing condition. Three years after Pollain's discovery, fabrication of fluoride glass fibers was performed at the Center National d'Etudes des Telecommunications (CNET), France, and the Nippon Telephone and Telegraph Public Corporation (NTT), Japan [32]. Since then, substantial progress has been made in improving the optical attenuation, mechanical strength, chemical durability, and manufacturing processing of fluoride glass fibers. So far, the background loss of a commercial ZBLAN fiber can be $<50 \mathrm{~dB} / \mathrm{km}$ in the $0.5-3.5 \mu \mathrm{m}$ wavelength region. UV-curable poly-acrylate is usually used to coat ZBLAN fiber so that the mean tensile strength can be up to $700 \mathrm{MPa}$. Although poor chemical durability of ZBLAN inevitably leads to the degradation of fiber strengths by moisture attack, coating with various metals or highly stable oxides and fluorides was suggested to significantly improve the durability of a ZBLAN fiber.

Like the fabrication of silica fibers, the preform method in which the fiber is drawn from a preformed glass rod at a temperature below the glass melting temperature is mostly used for ZBLAN fiber fabrications. ZBLAN fiber performs can be prepared by different casting processes including cladding-over-core casting (Mitachi et al. [33]), build-in casting (Mitachi et al. [33, 34]), and rotational casting (Tran et al. [35]). During the casting processes the critical temperature range between liquidus and transition temperature must be passed through rapidly because of the large crystallization tendency of ZBLAN glass. Normally the 
preform is made in separated glove box that allows complete processing of the glasses with an inert environment. In other words, ambient condition has to be avoided at all times and only the completed annealed preform is allowed to come into contact with air.

For a fiber preform, refractive indices of the core and the cladding must be precisely controlled to obtain a required index difference. In typical fluoride glasses, $\mathrm{PbF}_{2}$ and $\mathrm{BiF}_{3}$ raise the index, and $\mathrm{LiF}$ and $\mathrm{AlF}_{3}$ lower the index. Replacing $\mathrm{ZrF}_{4}$ by $\mathrm{HfF}_{4}$ in a ZBLAN glass also leads to a small reduction in index; so the latter is often used in cladding glass.

During the drawing process, preform and drawing speed must be precisely controlled because of the narrow working range influenced by the ZBLAN glass viscosity and the crystallization rate. In order to reduce the crystallization rate ZBLAN fibers should be drawn with a high drawing speed at temperatures as low as possible. The drawing temperature is usually in the $340-400^{\circ} \mathrm{C}$ range. Because moisture induces devitrification through hydration reactions, all fibers guiding devices are flushed by dry nitrogen before the fiber is coated with a UV-curable acrylate polymer.

It should be noted that, for each particular glass composition, the largest piece that can be made is determined by its crystallization rate during cooling. Therefore, the dimension of a preform is limited and consequently so is the total length of a ZBLAN fiber. This consideration should be included in the design of double-clad ZBLAN fibers for high-power operations. Although ZBLAN fibers with unlimited length can be directly drawn utilizing the crucible technique [36], it is hard to eliminate crystallization during the fiber drawing. Moreover, this method cannot be used for specially-designed fibers such as double-clad fibers with D-shaped or rectangular pumping cladding and microstructured fibers.

\section{High-Power ZBLAN Fiber Lasers}

Because of their wide transparency window, ZBLAN fibers have been suggested for a lot of applications including infrared imaging, remote infrared spectrometry, remote infrared spectrometric imaging, remote thermometry, laser power delivery, and fiber lasers. In the past decade, with advances in high-brightness semiconductor diode lasers, novel fiber designs, and new pumping schemes, fiber lasers have been developed with an tremendous speed due to the increasing demand of high-power fiber lasers in a variety of applications, such as material processing, telecommunications, spectroscopy, laser pumps, directed energy weapons, and medicine. ZBLAN fiber lasers have also experienced elevation of the output power level and expansion of the operation spectral region. In this section, ZBLAN fiber lasers are reviewed with three categories: infrared, upconversion UV and visible, and supercontinuum.

3.1. Infrared ZBLAN Fiber Lasers. Shortly after the emergence of fluoride glasses it was suggested that they may make particularly good hosts for a lasing material due

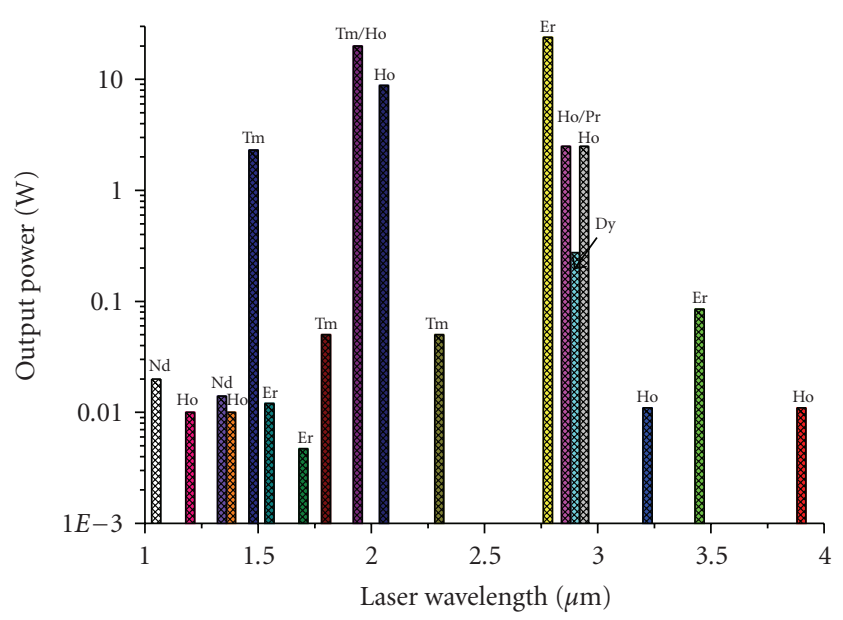

Figure 1: Highest output powers of infrared rare-earth-doped ZBLAN fiber lasers at different emission wavelengths.

to the extended infrared edge and low phonon energy [37]. Although many researchers had studied fluorescence in fluoride glasses it was not until 1987 when the first fluoride glass laser was developed on $\mathrm{Nd}^{3+}$-doped multimode fluoride fiber pumped by a argon ion laser at $514 \mathrm{~nm}$ [38]. Laser emission at $1.05 \mu \mathrm{m}$ was measured with a threshold launched pump power of $300 \mathrm{~mW}$ and an efficiency of about $0.03 \%$. $\mathrm{Er}^{3+}$-doped ZBLAN fiber laser at $1.56 \mu \mathrm{m}$ [39] and $\mathrm{Nd}^{3+}$-doped ZBLAN fiber laser at $1.35 \mu \mathrm{m}[40,41]$ were soon followed. The $1.35 \mu \mathrm{m}$ emission is significant because it cannot be obtained from a silica host. Shortly after various rare-earth-doped ZBLAN fiber lasers were demonstrated in different wavelength regions where silica fiber lasers are absent. For instance, $2.9 \mu \mathrm{m}$, $3.22 \mu \mathrm{m}$, and $3.9 \mu \mathrm{m}$ emissions were obtained from $\mathrm{Ho}^{3+}$ doped ZBLAN fiber lasers [42-44], $2.7 \mu \mathrm{m}$ and $3.45 \mu \mathrm{m}$ emissions from $\mathrm{Er}^{3+}$-doped ZBLAN fiber lasers [45-47], and $2.3 \mu \mathrm{m}$ emission from $\mathrm{Tm}^{3+}$-doped ZBLAN fiber lasers [48].

Activated by the increasing demand of high-power lasers for various applications, power scaling of fiber lasers has been mainly driven by the progresses of high-brightness semiconductor diode pumps, novel pump schemes, and new fiber designs. Rare-earth-doped ZBLAN fiber lasers have also benefited from these progresses. The highest output powers of infrared ZBLAN fiber lasers at different wavelengths are summarized in Figure 1. Critical parameters of these fiber lasers are listed in Table 2. Progress of infrared ZBLAN fiber lasers and their lasing mechanisms are described sequentially as follows.

3.1.1. Infrared $\mathrm{Er}^{3+}$-Doped ZBLAN Fiber Lasers. The partial energy level diagram of $\mathrm{Er}^{3+}$ ions to describe the transitions involving in infrared emissions is plotted in Figure 2. When the $\mathrm{Er}^{3+}$ ions are excited to the upper energy levels via ground-state absorption (GSA) and excited-state absorption (ESA) at pump wavelengths of $655 \mathrm{~nm}, 790 \mathrm{~nm}$, and $975 \mathrm{~nm}$, radiative transition ${ }^{4} S_{3 / 2} \rightarrow{ }^{4} I_{9 / 2}$ produces an emission of 
TABLE 2: Summary of infrared rare-earth-doped ZBLAN fiber lasers with the highest output powers so far.

\begin{tabular}{|c|c|c|c|c|c|c|}
\hline Rare-earth & $\begin{array}{c}\text { Laser } \\
\text { wavelength } \\
(\mu \mathrm{m})\end{array}$ & $\begin{array}{c}\text { Pump } \\
\text { wavelength } \\
\text { (nm) }\end{array}$ & $\begin{array}{c}\text { Output } \\
\text { power }(\mathrm{W})\end{array}$ & $\begin{array}{c}\text { Rare-earth } \\
\text { Concentration } \\
(\mathrm{mol} \%)\end{array}$ & $\begin{array}{c}\text { Slope } \\
\text { efficiency } \\
(\%)\end{array}$ & Reference \\
\hline \multirow{4}{*}{ Er } & 1.55 & 980 & 0.012 & 0.5 & 30 & [49] \\
\hline & 1.7 & 791 & 0.007 & 0.5 & 1.8 & {$[50]$} \\
\hline & 2.7 & 975 & 24 & 6 & 14.5 & [16] \\
\hline & 3.45 & 640 & 0.085 & 1 & 2.8 & [47] \\
\hline \multirow{3}{*}{$\mathrm{Tm}$} & 1.48 & 1064 & 2.3 & 0.2 & 65 & {$[51]$} \\
\hline & 1.94 & 792 & 20 & 2.5 & 49 & [15] \\
\hline & 2.3 & 790 & 0.001 & 0.1 & 10 & {$[48]$} \\
\hline \multirow{4}{*}{ Ho } & 2 & 806 & 8.8 & 0.4 & 36 & {$[52]$} \\
\hline & 2.86 & 1100 & 2.5 & 3 & 29 & [53] \\
\hline & 3.22 & 532 & 0.011 & 0.2 & 2.8 & {$[43]$} \\
\hline & 3.9 & 885 & 0.011 & 0.2 & 1.5 & [54] \\
\hline Dy & 2.9 & 1100 & 0.275 & 0.1 & 4.5 & {$[55]$} \\
\hline $\operatorname{Pr}$ & 1.3 & 1064 & 0.0045 & 0.09 & 0.45 & {$[56]$} \\
\hline $\mathrm{Yb}$ & 1 & 0.911 & 0.09 & 1.8 & 56 & [57] \\
\hline \multirow{2}{*}{$\mathrm{Nd}$} & 1.05 & 514.5 & 0.02 & 1.5 & 2.5 & {$[38]$} \\
\hline & 1.34 & 800 & 0.0136 & 0.2 & 12 & {$[58]$} \\
\hline
\end{tabular}

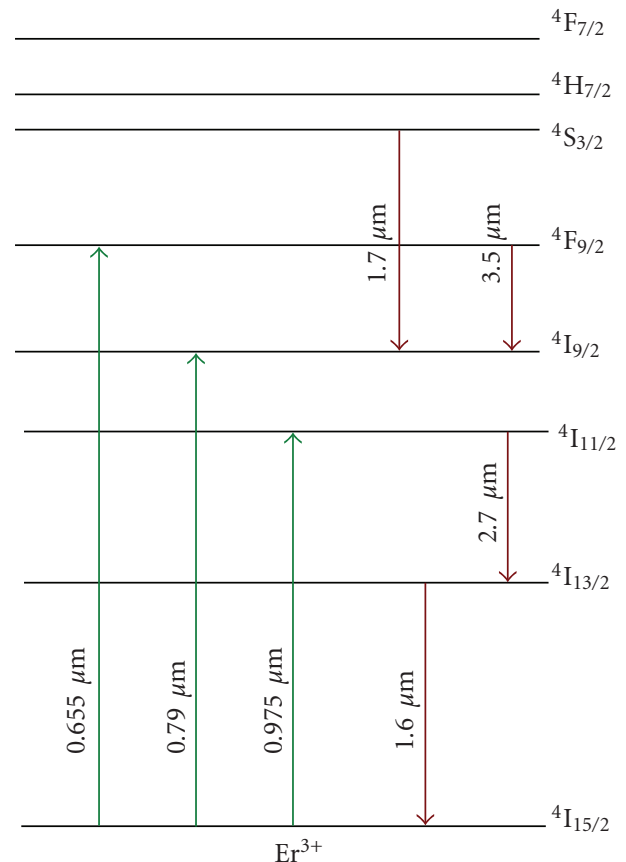

FIgure 2: Partial energy level diagram of $\mathrm{Er}^{3+}$ ion in ZBLAN related to infrared laser emissions. Pump absorption transitions are indicated with green upward arrows. Radiative emission transitions are indicated with red downward arrows.

$1.7 \mu \mathrm{m},{ }^{4} \mathrm{I}_{11 / 2} \rightarrow{ }^{4} \mathrm{I}_{13 / 2}$ produces an emission of $2.7 \mu \mathrm{m}$, ${ }^{4} \mathrm{I}_{13 / 2} \rightarrow{ }^{4} \mathrm{I}_{15 / 2}$ produces an emission of $1.55 \mu \mathrm{m}$, and ${ }^{4} \mathrm{~F}_{9 / 2} \rightarrow$ ${ }^{4} \mathrm{I} / / 2$ produces an emission of $3.45 \mu \mathrm{m}$.
Although $1.55 \mu \mathrm{m}$ emission was first demonstrated in $\mathrm{Er}^{3+}$-doped ZBLAN fiber [39], there is few further investigations at this wavelength because $\mathrm{Er}^{3+}$-doped ZBLAN fiber is not as competitive as stable and low-cost $\mathrm{Er}^{3+}$-doped silica fiber which has been extensively used for optical amplifiers at $1.5 \mu \mathrm{m}$ telecommulication window. Most recently, some investigations $[49,59]$ have been conducted on an $\mathrm{Er}^{3+} / \mathrm{Ce}^{3+}$ codoped ZBLAN fiber laser that has a wide tuning range of $1490 \mathrm{~nm}-1610 \mathrm{~nm}$ compared to $1520 \mathrm{~nm}-1600 \mathrm{~nm}$ of silica fiber laser. However, the output power was only $12 \mathrm{~mW}$ and the slope efficiency was approximate $30 \%$. Nevertheless, $\mathrm{Er}^{3+} / \mathrm{Ce}^{3+}$-codoped ZBLAN fiber may be promising for ultrafast pulse generation because of its wide and flat gain profile.

Since $1.7 \mu \mathrm{m}$ emissions in $\mathrm{Er}^{3+}$-codoped ZBLAN fiber generally result from the accessorial transitions in the cascade lasing of $2.7 \mu \mathrm{m}$ laser $[50,60,61]$ and there is few report on independent operation at the this wavelength [62], we will not address this transition here.

Because $2.7 \mu \mathrm{m}$ emission is close to the highest absorption peak of water around $3 \mu \mathrm{m}$ and thereby can be extensively used in laser surgery, high-power laser emission at this wavelength has been pursued with significant efforts $[14,16,45,50,60-91]$.

Generally, the $2.7 \mu \mathrm{m}$ lasing is a self-terminating transition, because the longer natural lifetime of the lower laser level $\left({ }^{4} \mathrm{I}_{13 / 2}, \tau_{1}=9 \mathrm{~ms}\right)$ relative to that of the upper laser level $\left({ }^{4} \mathrm{I}_{11 / 2}, \tau_{2}=6.9 \mathrm{~ms}\right)$ of erbium ions in ZBLAN glass may restrict lasing to a pulsed mode. However, continuouswave $(\mathrm{CW})$ multimode emission was observed in the first $2.7 \mu \mathrm{m} \mathrm{Er}^{3+}$-doped ZBLAN fiber laser pumped by an argon 
ion laser at $476.5 \mathrm{~nm}$ [45]. This unusual CW lasing of the selfterminating transition was explained by ESA depleting the lower level ${ }^{4} \mathrm{I}_{13 / 2}$ and maintaining the population inversion. The first single-mode $\mathrm{Er}^{3+}$-doped ZBLAN fiber laser was demonstrated by Allain et al. [64] and an output power of $250 \mu \mathrm{W}$ was measured. Soon several low-efficiency diodepumped fiber lasers were reported [65-67]. Compared to the low efficiency $(<10 \%)$ and low power operations $(<10 \mathrm{~mW})$ of these singly $\mathrm{Er}^{3+}$-doped ZBLAN fiber lasers, higher output power of $30 \mathrm{~mW}$ with an efficiency more than $13 \%$ was obtained in an $\mathrm{Er}^{3+} / \mathrm{Pr}^{3+}$-codoped ZBLAN fiber laser [68]. Since these CW operations were demonstrated at relatively low power levels, the population bottleneck caused by the shorter lifetime of the upper laser level relative to the lower laser level was not noticed until Bedo [69, 70] reported the saturation of the $2.71 \mu \mathrm{m}$ laser output from $\mathrm{Er}^{3+}$-doped ZBLAN fibers with different concentrations pumped by a Ti:sapphire laser at $791 \mathrm{~nm}$. Colasing at $1.7 \mu \mathrm{m}$ via transition ${ }^{4} \mathrm{~S}_{3 / 2} \rightarrow{ }^{4} \mathrm{I}_{9 / 2}$ was suggested to suppress the competitive lasing on the $850 \mathrm{~nm}$ transition ${ }^{4} \mathrm{~S}_{3 / 2} \rightarrow{ }^{4} \mathrm{I}_{13 / 2}$ and relieve the population bottleneck $[50,60,61]$. Thereafter, $150 \mathrm{~mW}$ unsaturated output was achieved from a cascade $\mathrm{Er}^{3+}$-doped ZBLAN fiber laser [71]. However, this type of cascadelasing is only efficient in low-doped, core-pumped fiber lasers and cannot be used for low-brightness diode-pumped high-power (watt-level) fiber lasers. Jackson recently demonstrated a novel cascade fiber laser in which the $1.6 \mu \mathrm{m}$ transition was utilized to prevent population bottleneck by radiative decay and watt-level output was obtained [72].

In order to elevate the output power of $2.7 \mu \mathrm{m}$ fiber lasers, significant investigations on lasing mechanisms and power scaling schemes have been completed. So far, energytransfer process between $\mathrm{Er}^{3+}$ ions and codoped $\mathrm{Pr}^{3+}$ ions and energy-transfer upconversion process between $\mathrm{Er}^{3+}$ and $\mathrm{Er}^{3+}$ ions have been proven most efficient to depopulate the lower laser level ${ }^{4} \mathrm{I}_{13 / 2}$ and solve the population bottleneck even with low-brightness pumping. Watt-level and 10watt-level $2.7 \mu \mathrm{m}$ lasers have been demonstrated in highconcentration singly Er-doped ( $>1$ mol\%) ZBLAN doubleclad fibers [14, 16, 78, 87, 88, 90, 91] and Er/Pr codoped ZBLAN double-clad fibers [76, 77, 89, 90]. It should be noted that, the output of the first 10 -watt-level $2.7 \mu \mathrm{m}$ laser [14] was only constrained by the thermo-optic effects at high-power operation. Much stronger emissions are recently achieved when a large-core fiber is used and efficient heat dissipation is employed [16]. Increasing the efficiency of a laser can boost up the output power without increasing the pump power and some theoretical calculations suggest that heavily Er-doped (>10 mol.\%) $2.7 \mu \mathrm{m}$ fiber lasers possibly make a slope efficiency close to or even larger than the Stokes limits [84, 85]. However, much work is still needed to experimentally determine the optimum concentration for maximum efficiency and to fabricate low-loss ZBLAN fibers with such high-concentration. Technically, crystallization is an obstacle of fabricating high concentration ZBLAN fibers and $10 \mathrm{~mol} \%$ is the maximum concentration of rare-earth ions in ZBLAN without inducing detrimental crystallization. Though zero-gravity environment has been proven to significantly reduce the crystallization during ZBLAN fabrication

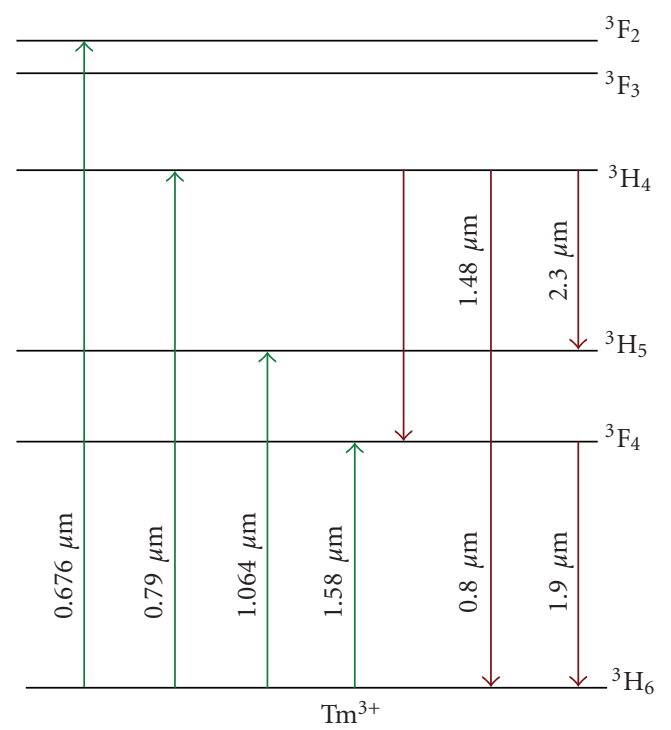

Figure 3: Partial energy level diagram of $\mathrm{Tm}^{3+}$ ion in ZBLAN related to infrared laser emissions. Pump absorption transitions are indicated with green upward arrows. Radiative emission transitions are indicated with red downward arrows.

process [92], there is little feasibility of fabricating heavily Erdoped ZBLAN fibers ( $>10 \mathrm{~mol} \%$ ) for high efficiency lasers in the near further. Therefore, using large-mode-area core or multicore ZBLAN fibers will be the effective approach to obtain 100-watt-level output at $2.7 \mu \mathrm{m}$ in the future.

In 1999, Tobben reported the laser emission of $3.5 \mu \mathrm{m}$ in a 12 -cm-long $\mathrm{Er}^{3+}$-doped ZBLAN fiber pumped with a DCM dye laser at $655 \mathrm{~nm}$ [46]. However, the operation temperature was $77 \mathrm{~K}$. Room temperature CW operation of this fiber laser was demonstrated shortly after with an output power of $2.5 \mathrm{~mW}$ and a slope efficiency of $2.8 \%$ [47]. But the threshold is much larger than the cooled operation. Since emission of $3.5 \mu \mathrm{m}$ can be obtained only when $\mathrm{Er}^{3+}$-doped ZBLAN is pumped with a short wavelength pump at $655 \mathrm{~nm}$, it is challenging to achieve high-power output at this wavelength due to the small Stokes efficiency and the unavailability of high-power laser diode at $655 \mathrm{~nm}$. Nevertheless, $3.5 \mu \mathrm{m}$ fiber laser is of much interest because various hydrocarbon and hydrochloride groups and several commonly used solvents show strong absorption in the wavelength range from $3.2 \mu \mathrm{m}$ to $3.6 \mu \mathrm{m}$. Furthermore, the atmosphere has a minimum attenuation in the window between $3 \mu \mathrm{m}$ and $4 \mu \mathrm{m}$. Watt-level output at $3.5 \mu \mathrm{m}$ can be achieved in $\mathrm{Er}^{3+}$-doped ZBLAN fibers in the future by using novel fiber designs and new pump schemes.

3.1.2. Infrared $\mathrm{Tm}^{3+}$-Doped ZBLAN Fiber Lasers. The partial energy level diagram of $\mathrm{Tm}^{3+}$ ions to describe the transitions producing infrared emissions is plotted in Figure 3. Three radiative de-excitation processes from the ${ }^{3} \mathrm{H}_{4}$ level emit at $0.8 \mu \mathrm{m}, 1.47 \mu \mathrm{m}$, and $2.3 \mu \mathrm{m}$ with branching ratio of 0.893 , 0.083 , and 0.024 . Emission of $1.9 \mu \mathrm{m}$ can be obtained from the transition ${ }^{3} \mathrm{~F}_{4} \rightarrow{ }^{3} \mathrm{H}_{6}$. 
The $1.47 \mu \mathrm{m}$ laser oscillation cannot be realized in silica glass fibers because the transition ${ }^{3} \mathrm{H}_{4} \rightarrow{ }^{3} \mathrm{~F}_{4}$ is a fast nonradiative relaxation which rapidly reduces the population of excited ${ }^{3} \mathrm{H}_{4}$ level. However, like the CW operation of $2.7 \mu \mathrm{m}$ in $\mathrm{Er}^{3+}$-doped ZBLAN, due to the longer lifetimes of ions in ZBLAN relative to those in silica, the $1.47 \mu \mathrm{m}$ emission can be achieved in $\mathrm{Tm}^{3+}$-doped ZBLAN even it is a self-terminating transition. In 1989, Allain et al. [93] demonstrated laser oscillation around $1.48 \mu \mathrm{m}$ using a $\mathrm{Tm}^{3+}$-doped multimode fluoride fiber for the first time using a krypton ion laser operating at $676 \mathrm{~nm}$ as a pump source. Since the transition ${ }^{3} \mathrm{H}_{4} \rightarrow{ }^{3} \mathrm{~F}_{4}$ is a self-terminating system, the slope efficiency of this fiber laser was very low and the output power was a few tens of $\mu \mathrm{W}$. Three approaches have been proven able to solve the self-terminating problem. One is colasing at $1.9 \mu \mathrm{m}$ via the transition ${ }^{3} \mathrm{~F}_{4} \rightarrow{ }^{3} \mathrm{H}_{6}$ that can depopulate the ${ }^{3} \mathrm{~F}_{4}$ level efficiently $[94,95]$. Another is to shorten the actual lifetime of the lower level by energy transfer to codopant such as $\mathrm{Tb}^{3+}$ or $\mathrm{Ho}^{3+}$ ions [96]. The most efficient way is upconversion pumping at $1064 \mathrm{~nm}$ using ESA from the ${ }^{3} \mathrm{~F}_{4}$ to the ${ }^{3} \mathrm{~F}_{2}$ level to depopulate the lower laser level [97-99].

In 1992, Komukai et al. [97] observed highly efficient $1.47 \mu \mathrm{m}$ continuous-wave oscillation in $\mathrm{Tm}^{3+}$-doped ZBLAN fiber using $1064 \mathrm{~nm}$ upconversion pumping. A watt-level fiber laser was soon demonstrated with this scheme [100]. The upconversion pumping process can be described as follows. First ground state ions are excited to the ${ }^{3} \mathrm{H}_{5}$ level and decay to the metastable ${ }^{3} \mathrm{~F}_{4}$ level by multiphonon relaxation. These ions are then reexcited to the ${ }^{3} \mathrm{~F}_{2}$ level by ESA process and rapidly decay to the ${ }^{3} \mathrm{H}_{4}$ level. This ESA process ${ }^{3} \mathrm{~F}_{4} \rightarrow{ }^{3} \mathrm{~F}_{2}$ maintains the population inversion by reducing the ${ }^{3} \mathrm{~F}_{4}$ population and increasing the ${ }^{3} \mathrm{H}_{4}$ population. In order to avoid the effect of cross-relaxation process that starts from the upper laser level ${ }^{3} \mathrm{H}_{4}$, a large core area ZBLAN fiber doped with low-concentration $\mathrm{Tm}^{3+}$ ions $(0.1 \mathrm{wt} \%)$ was used in a $1.56 \mathrm{~W} 1.47 \mu \mathrm{m}$ fiber laser pumped at $1064 \mathrm{~nm}$ [101]. Most recently, $1.48 \mu \mathrm{m}$ single-mode fiber lasers based on fiber Bragg gratings directly inscribed in the ZBLAN fiber core by femtosecond pulses at $800 \mathrm{~nm}$ were demonstrated $[51,102]$. Maximum output power of $2.3 \mathrm{~W}$ and a conversion efficiency of $65 \%$ have been achieved when the $\mathrm{Tm}^{3+}$-doped ZBLAN fiber was pumped with an $\mathrm{Yb}^{3+}$ doped silica fiber laser at $1064 \mathrm{~nm}$. Since the output power was only limited by the available pump power, ten-watt or even 100 -watt all-fiber laser at $1.48 \mu \mathrm{m}$ can be realized in the near future.

In 1989, Allen and Esterowitz [48] reported the first successful operation of a GaAlAs diode $(790 \mathrm{~nm})$ pumped $\mathrm{CW} \mathrm{Tm}^{3+}$-doped ZBLAN fiber laser at $2.3 \mu \mathrm{m}$. Output power of $1 \mathrm{~mW}$ and slope efficiency of $10 \%$ were demonstrated. In the same year, a tunable CW lasing around $0.82 \mu \mathrm{m}, 1.48 \mu \mathrm{m}$, $1.88 \mu \mathrm{m}$, and $2.35 \mu \mathrm{m}$ was demonstrated in a $\mathrm{Tm}^{3+}$-doped ZBLAN fiber [93]. In 1991, Percival et al. [103] demonstrated a wavelength tunable fiber laser pumped by a $790 \mathrm{~nm}$ Ti:sapphire laser. The wavelength was continuously tunable from $2.25 \mu \mathrm{m}$ to $2.5 \mu \mathrm{m}$. For the $2.3 \mu \mathrm{m}$ emission, the transition ${ }^{3} \mathrm{H}_{4} \rightarrow{ }^{3} \mathrm{H}_{5}$ is followed by a rapid nonradiative decay to the ${ }^{3} \mathrm{~F}_{4}$ level. Since the lifetime of the ${ }^{3} \mathrm{H}_{4}$ level $(1.5 \mathrm{~ms})$

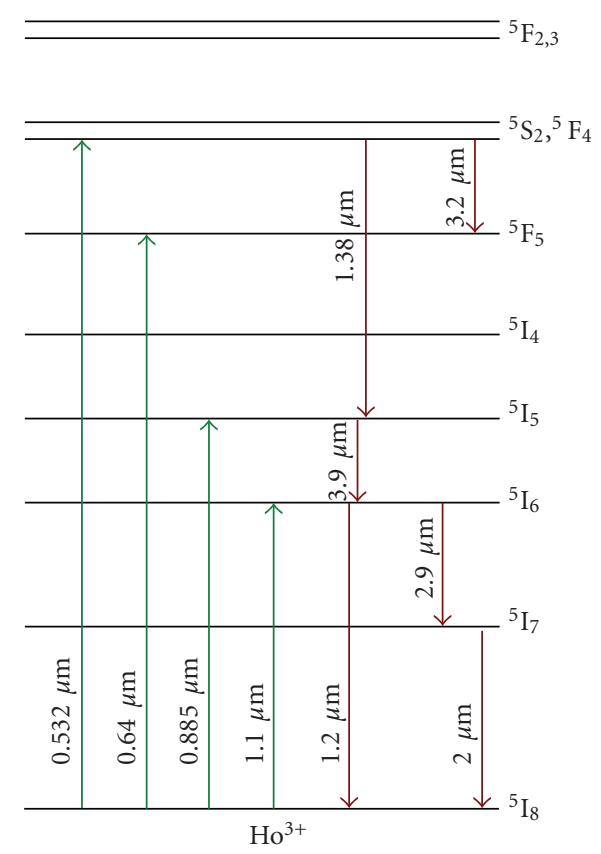

Figure 4: Partial energy level diagram of $\mathrm{Ho}^{3+}$ ion in ZBLAN related to infrared laser emissions. Pump absorption transitions are indicated with green upward arrows. Radiative emission transitions are indicated with red downward arrows.

is shorter than that of the ${ }^{3} \mathrm{~F}_{4}$ level $(6.8 \mathrm{~ms})$, population builds up in the ${ }^{3} \mathrm{~F}_{4}$ level and consequently the performance of the laser is severely curtailed. This undesirable effect can be eliminated by enforcing simultaneous lasing at $1.9 \mu \mathrm{m}$ on the ${ }^{3} \mathrm{~F}_{4} \rightarrow{ }^{3} \mathrm{H}_{6}$ transition. Due to the increasing demand of fiber lasers beyond $2 \mu \mathrm{m}$, watt-level $2.3 \mu \mathrm{m}$ fiber laser should emerge very soon.

In 2008, Eichhorn and Jackson [15] did a comparative study of CW $\mathrm{Tm}^{3+}$-doped silica and fluoride fiber lasers at $1.9 \mu \mathrm{m}$. Ten-watt-level $\mathrm{Tm}^{3+}$-doped ZBLAN fiber laser pumped by two laser diodes at $792 \mathrm{~nm}$ was demonstrated. Output power of $20 \mathrm{~W}$ with a slope efficiency of $49 \%$ was obtained in a $30 \mu \mathrm{m}$ core ZBLAN fiber highly doped with $\mathrm{Tm}^{3+}$ ions concentration of $2.5 \mathrm{~mol} \%$. Although the output of the fluoride fiber laser is not comparable with that of the silica fiber laser, his experimental results indicate that tens of watts ZBLAN fiber lasers are feasible when newly designed fibers and novel pumping schemes are utilized with optimized operation conditions.

3.1.3. Infrared $\mathrm{Ho}^{3+}$-Doped ZBLAN Fiber Lasers. The partial energy-level diagram of $\mathrm{Ho}^{3+}$ ions to describe the transitions involving in infrared emissions is plotted in Figure $4 . \mathrm{Ho}^{3+}$ doped ZBLAN has more infrared transitions comparing to other rare-earth-doped ZBLANs. $1.2 \mu \mathrm{m}, 1.38 \mu \mathrm{m}, 2 \mu \mathrm{m}$, $2.9 \mu \mathrm{m}, 3.2 \mu \mathrm{m}$, and $3.9 \mu \mathrm{m}$ emissions can be achieved from the transitions, ${ }^{5} \mathrm{I}_{6} \rightarrow{ }^{5} \mathrm{I}_{8},{ }^{5} \mathrm{~F}_{4} \rightarrow{ }^{5} \mathrm{I}_{5},{ }^{5} \mathrm{I}_{7} \rightarrow{ }^{5} \mathrm{I}_{8},{ }^{5} \mathrm{I}_{6} \rightarrow{ }^{5} \mathrm{I}_{7}$, ${ }^{5} \mathrm{~F}_{4} \rightarrow{ }^{5} \mathrm{~F}_{5}$, and ${ }^{5} \mathrm{I}_{5} \rightarrow{ }^{5} \mathrm{I}_{6}$, respectively.

In 1988, Brierley et al. [104] observed the lasing at $2.08 \mu \mathrm{m}$ and $1.38 \mu \mathrm{m}$ from a $\mathrm{Ho}^{3+}$-doped ZBLAN fiber for the first time using an argon ion pump laser at $488 \mathrm{~nm}$. 
However, the efficiency is very low $(<0.3 \%)$ and the operation at $2 \mu \mathrm{m}$ was not $\mathrm{CW}$ at room temperature. Higher efficient $(30 \%)$ CW operation was demonstrated when a $\mathrm{Ho}^{3+}$-doped ZBLAN fiber was pumped by a Ti:sapphire laser at $890 \mathrm{~nm}$ [105]. Allain et al. [106] demonstrated a highefficiency CW $2 \mu \mathrm{m}$ ZBLAN fiber laser in which $\mathrm{Ho}^{3+}$ ions are sensitized with $\mathrm{Tm}^{3+}$ ions. $\mathrm{Tm}^{3+}$ ions are excited in the ${ }^{3} \mathrm{H}_{4}$ level by a pump of wavelength around $0.8 \mu \mathrm{m}$. If the $\mathrm{Tm}^{3+}$ concentration is high enough, cross relaxation process between two neighboring $\mathrm{Tm}^{3+}$ ions can double the pumping efficiency because one $\mathrm{Tm}^{3+}$ ion in the ${ }^{3} \mathrm{H}_{4}$ level relaxes to the ${ }^{3} \mathrm{~F}_{4}$ level with simultaneous excitation of another $\mathrm{Tm}^{3+}$ ion from the ${ }^{3} \mathrm{H}_{6}$ level to the ${ }^{3} \mathrm{~F}_{4}$ level. Energy transfer from $\mathrm{Tm}^{3+}$ ions to $\mathrm{Ho}^{3+}$ ions leads to the population of the ${ }^{5} \mathrm{I}_{7}$ level. Therefore, using $\mathrm{Tm}^{3+}$ codoping can significantly improve the performance of $2 \mu \mathrm{m} \mathrm{Ho}{ }^{3+}$-doped ZBLAN fiber laser. An output power of $250 \mathrm{~mW}$, a slope efficiency of $52 \%$, and a pump efficiency of $130 \%$ were achieved in this $\mathrm{Tm}^{3+} / \mathrm{Ho}^{3+}$ codoped system. In 2001, Jackson [52] demonstrated an $8.8 \mathrm{~W} \mathrm{Tm}{ }^{3+} / \mathrm{Ho}^{3+}$ codoped fiber laser at this wavelength by using two high-power pump diodes at $800 \mathrm{~nm}$.

Because of the larger water absorption coefficient at $3 \mu \mathrm{m}$ $\left(\sim 10^{4} \mathrm{~cm}^{-1}\right)$ relative to $2 \mu \mathrm{m}\left(\sim 10 \mathrm{~cm}^{-1}\right), 3 \mu \mathrm{m}$ band of $\mathrm{Ho}^{3+}$ ions has been of much interest for laser surgery. The first $3 \mu \mathrm{m} \mathrm{Ho}^{3+}$-doped ZBLAN fiber laser was demonstrated by two pump lasers at $640 \mathrm{~nm}$ and $750 \mathrm{~nm}$ [107]. Because the lifetime of the ${ }^{5} \mathrm{I}_{6}$ level $(3.5 \mathrm{~ms})$ is shorter than that of the ${ }^{5} \mathrm{I}_{7}$ level $(12 \mathrm{~ms})$, the $3 \mu \mathrm{m}$ emission is a self-terminating transition. The CW operation was explained by ESA of the pump starting from the ${ }^{5} \mathrm{I}_{7}$ level. When pumped at $640 \mathrm{~nm}$, maximum output power of $12.6 \mathrm{~mW}$ and the highest slope efficiency of $4.4 \%$ were achieved. In order to solve the selfterminating and improve the efficiency of $3 \mu \mathrm{m}$ transition, a cascade lasing with transitions from ${ }^{5} \mathrm{I}_{6}$ to ${ }^{5} \mathrm{I}_{7}$, to ${ }^{5} \mathrm{I}_{8}$, where the $2 \mu \mathrm{m}$ oscillation depletes the ${ }^{5} \mathrm{I}_{7}$ population, was employed [108, 109]. Maximum total output power of $3 \mathrm{~W}$ with a slope efficiency of $65 \%$ was obtained in a $\mathrm{Ho}^{3+}$-doped ZBLAN fiber pumped by a Raman fiber laser at $1150 \mathrm{~nm}$ [109].

In order to improve the efficiency of the $3 \mu \mathrm{m}$ emission and eliminate the $2 \mu \mathrm{m}$ lasing, $\mathrm{Ho}^{3+}$-doped fibers were codoped with $\mathrm{Pr}^{3+}$ ions as deactivators because strong energy transfer from the energy level ${ }^{5} \mathrm{I}_{7}$ of $\mathrm{Ho}^{3+}$ to the energy level ${ }^{3} \mathrm{~F}_{2}$ of $\mathrm{Pr}^{3+}$ allows fast depopulation of the lower laser level ${ }^{5} \mathrm{I}_{7}[53,110-113]$. So far, the highest output power of $2.5 \mathrm{~W}$ with a slope efficiency of $32 \%$ was achieved in a $\mathrm{Ho}^{3+} / \mathrm{Pr}^{3+}$ codoped ZBLAN fiber pumped by a $\mathrm{Yb}^{3+}$-doped silica fiber laser at $1100 \mathrm{~nm}$ [53]. Alternatively, the $3 \mu \mathrm{m}$ oscillation can be enhanced while the $2 \mu \mathrm{m}$ lasing is circumscribed by doping the fiber core with high $\mathrm{Ho}^{3+}$ ion concentration to allow significant energy transfer upconversion process between ions and thus depopulate the lower laser level ${ }^{5} \mathrm{I}_{7}$. Exclusive operation at $2.92 \mu \mathrm{m}$ with maximum output power of $340 \mathrm{~mW}$ and a slope efficiency of $\sim 5 \%$ was achieved in a singly $\mathrm{Ho}^{3+}$-doped ZBLAN fiber with a concentration of $4.3 \mathrm{~mol} \%$ [114]. It was recently found that highly stable emission at $2.95 \mu \mathrm{m}$ can be obtained without colasing at $2 \mu \mathrm{m}$ when $\mathrm{Ho}^{3+}$-doped ZBLAN fiber was pumped at a Raman fiber laser at $1175 \mathrm{~nm}$ [115], because the ESA of pump photons in a transition ${ }^{5} \mathrm{I}_{7} \rightarrow{ }^{5} \mathrm{I}_{4}$ can depopulate the lower laser level and maintain the population inversion in the transition of interest.

Because the strong absorption band of hydrocarbon and hydrochloride groups and a transparency window of atmosphere locate in the $3 \mu \mathrm{m}-4 \mu \mathrm{m}$ wavelength region, emissions beyond $3 \mu \mathrm{m}$ are of much interest. In 1998, Carbonnier et al. [43] reported a room temperature CW $\mathrm{Ho}^{3+}$-doped ZBLAN fiber laser operating at $3.22 \mu \mathrm{m}$ with an output power of $11 \mathrm{~mW}$ and a slope efficiency of $2.8 \%$. This fiber laser was pumped by an Nd:YAG laser at $532 \mathrm{~nm}$. The input coupler had a reflectivity of $100 \%$ at the lasing wavelength and output coupler had a reflectivity of $90 \%$ at the lasing wavelength.

In 1993, Tobben [116] observed the fluorescence at $3.9 \mu \mathrm{m}$ in an $\mathrm{Ho}^{3+}$-doped ZBLAN fiber for the first time. This experiment suggested that a transition near $3.9 \mu \mathrm{m}$ is possible even though the lasing conditions are worse compared with other radiative transitions due to the longer wavelength and the increased multiphonon rates. In 1995, the first $3.9 \mu \mathrm{m}$ fiber laser was realized in an $\mathrm{Ho}^{3+}$-doped ZBLAN fiber pumped by a DCM dye laser at $640 \mathrm{~nm}$ [44]. The $3.9 \mu \mathrm{m}$ emission is maintained by a cascade lasing at $1.2 \mu \mathrm{m}$ that depletes the lower laser level ${ }^{5} \mathrm{I}_{6}$ to the ground state ${ }^{5} \mathrm{I}_{8}$. The output is about $1 \mathrm{~mW}$ and the slope efficiency is $1.5 \%$. Shortly after an $11 \mathrm{~mW}$ output was achieved with an optimization of the mirror design and the fiber [54]. However, in order to achieve efficient CW $3.9 \mu \mathrm{m}$ emission, the fiber has to cool down to $77 \mathrm{~K}$ because the multiphonon rate increases strongly for temperature above $100 \mathrm{~K}$ and for wavelengths above $3 \mu \mathrm{m}$. Nevertheless laser oscillation without additional cooling (at room temperature) is possible if the gain is large enough at $3.9 \mu \mathrm{m}$.

3.1.4. Infrared $D y^{3+}$-Doped ZBLAN Fiber Lasers. The partial energy-level diagram of $\mathrm{Dy}^{3+}$ ions is plotted in Figure 5. Infrared Laser emission at $2.9 \mu \mathrm{m}$ can be obtained from the radiative transition ${ }^{6} \mathrm{H}_{13 / 2} \rightarrow{ }^{6} \mathrm{H}_{15 / 2}$.

There are few reports on $\mathrm{Dy}^{3+}$-dope ZBLAN fiber lasers. The first $\mathrm{CW} \mathrm{Dy}^{3+}$-dope ZBLAN fiber laser was demonstrated in 2003 [55]. Maximum output power of $0.275 \mathrm{~W}$ was generated at a slope efficiency of $4.5 \%$ when the ZBLAN fiber laser was pumped with a diode-cladding-pumped $\mathrm{Yb}^{3+}$ doped silica fiber laser at $\sim 1100 \mathrm{~nm}$. In the continued investigation [117], a slope efficiency was increased to $20 \%$ when the ZBLAN fiber laser was pumped by a $1.3 \mu \mathrm{m}$ $\mathrm{Nd}$ :YAG laser because of the increased Stokes efficiency and the reduced ESA of pump photons. However, the output power was $0.18 \mathrm{~W}$ limited by the available pump power. High efficiency Raman fiber laser at $1.29 \mu \mathrm{m}$ was suggested as a powerful pump for the $2.9 \mu \mathrm{m} \mathrm{Dy}{ }^{3+}$-doped ZBLAN fiber laser. With recent advances in $1 \mu \mathrm{m}$ silica fiber laser, wattlevel or ten-watt-level $\mathrm{Dy}^{3+}$-doped ZBLAN fiber laser can be developed in the near future.

3.1.5. Infrared $\mathrm{Nd}^{3+}$-Doped ZBLAN Fiber Lasers. The partial energy-level diagram of $\mathrm{Nd}^{3+}$ ions to describe the transitions involving in infrared emissions is plotted in Figure 6. When 


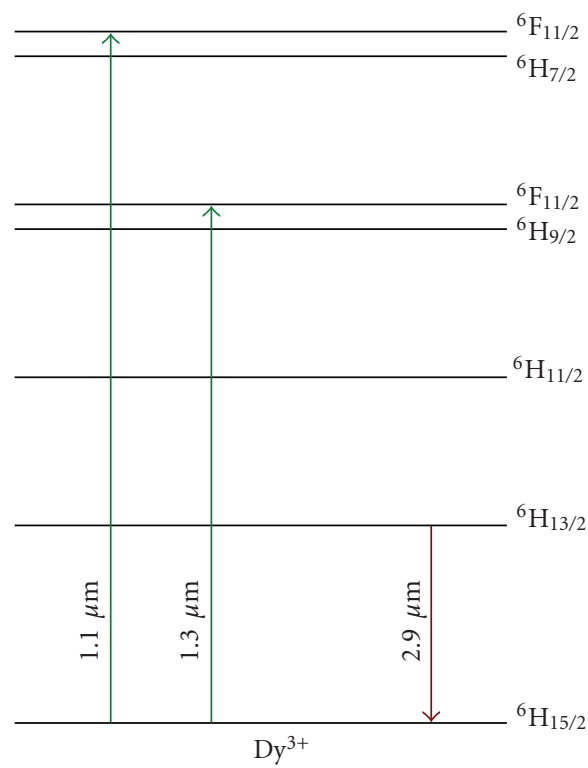

Figure 5: Partial energy level diagram of $\mathrm{Dy}^{3+}$ ion in ZBLAN related to the $2.9 \mu \mathrm{m}$ laser emission. Pump absorption transitions are indicated with green upward arrows. Radiative emission transition is indicated with red downward arrow.

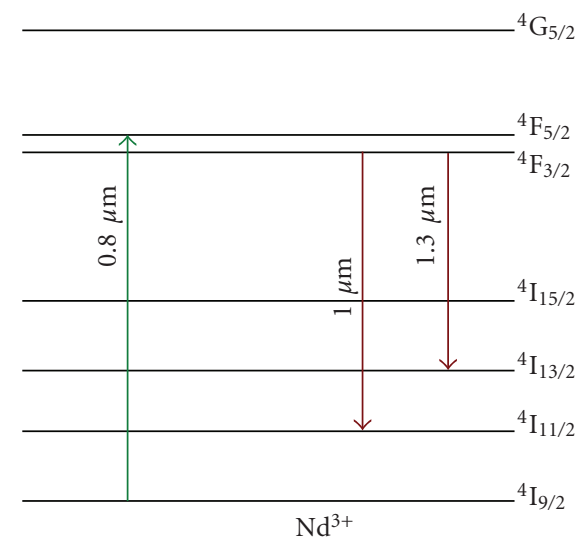

Figure 6: Partial energy level diagram of $\mathrm{Nd}^{3+}$ ion in ZBLAN related to infrared laser emissions. Pump absorption transition is indicated with green upward arrow. Radiative emission transitions are indicated with red downward arrows.

the ions are excited to the upper energy levels via GSA ${ }^{4} \mathrm{I}_{9 / 2} \rightarrow{ }^{4} \mathrm{~F}_{5 / 2}$, radiative transition ${ }^{4} \mathrm{~F}_{3 / 2} \rightarrow{ }^{4} \mathrm{I}_{13 / 2}$ produces an emission at $1.3 \mu \mathrm{m}$, and ${ }^{4} \mathrm{~F}_{3 / 2} \rightarrow{ }^{4} \mathrm{I}_{11 / 2}$ produces an emission at $1.0 \mu \mathrm{m}$.

As mentioned above, the first fluoride fiber laser was demonstrated on a multimode $\mathrm{Nd}^{3+}$-doped ZBLAN fiber [38]. Laser emission at $1.05 \mu \mathrm{m}$ was observed when the fiber was pumped by an argon ion laser at $514 \mathrm{~nm}$. This ZBLAN fiber laser was considered as significant because the emission wavelength is beyond the typical emission wavelength range $(1.06 \mu \mathrm{m}-1.08 \mu \mathrm{m})$ of widely used $\mathrm{Nd}^{3+}$-doped silica fiber lasers. When high reflection mirror at $1.3 \mu \mathrm{m}$ band was used, $1.33 \mu \mathrm{m}-1.34 \mu \mathrm{m}$ range laser was obtained from the same $\mathrm{Nd}^{3+}$-doped ZBLAN fiber [118]. An output power of larger than $10 \mathrm{~mW}$ and a slope efficiency of $2.6 \%$ were obtained. Essentially, there are two constraints for power scaling of $\mathrm{Nd}^{3+}$-doped ZBLAN fiber lasers operating at $1.3 \mu \mathrm{m}$ band. One is the ESA transition ${ }^{4} \mathrm{~F}_{3 / 2} \rightarrow{ }^{4} \mathrm{G}_{7 / 2}$ which absorbs the signal light around $1.31 \mu \mathrm{m}$. The other is the strong competitive $1.05 \mu \mathrm{m}$ transition which can easily suppress $1.3 \mu \mathrm{m}$ band oscillation. A more efficient $\mathrm{Nd}^{3+}$-doped ZBLAN fiber laser operating in the $1.3 \mu \mathrm{m}$ band pumped at $800 \mathrm{~nm}$ was demonstrated by Komukai et al. [58]. The slope efficiency and the maximum output power are $15.7 \%$ and $13.6 \mathrm{~mW}$, respectively. This fiber laser was of practical interest due to the wavelength tunable range $1.315 \mu \mathrm{m}-1.348 \mu \mathrm{m}$ in the $1.3 \mu \mathrm{m}$ telecommunication window.

3.1.6. Other Infrared ZBLAN Fiber Lasers. Compared to the rare-earth ions described above, there are few studies on $\operatorname{Pr}^{3+}$ and $\mathrm{Yb}^{3+}$ singly-doped ZBLAN fiber lasers. However, $\mathrm{Pr}^{3+}$ and $\mathrm{Yb}^{3+}$ ions have been extensively used as codpants in ZBLAN fibers to effectively enhance the desired transitions including laser emission and pump absorption and suppress competitive emissions $[53,68,76,77,79-81,84-87,89,90$, $110-113,119]$.

$\mathrm{Pr}^{3+}$-doped ZBLAN fiber has been intensively investigated for $1.3 \mu \mathrm{m}$ optical amplifiers during the 1990's bloom of optical communications. CW lasing action in $\mathrm{Pr}^{3+}$-doped ZBLAN fiber was reported by Durteste in 1991 [56]. Due to the broad gain band, ultra-short pulse generation from $\mathrm{Pr}^{3+}$-doped ZBLAN fibers was then demonstrated by using nonlinear optical loop mirrors $[120,121]$.

$\mathrm{Yb}^{3+}$-doped ZBLAN fiber laser was only demonstrated by Allain et al. [57] and proposed as a potential pump for $\mathrm{Pr}^{3+}$ doped ZBLAN fiber amplifier at $1.3 \mu \mathrm{m}$ because efficient emission can be obtained at $1020 \mathrm{~nm}$ in a ZBLAN fiber but not in a silica fiber.

3.2. Upconversion Ultraviolet and Visible ZBLAN Fiber Lasers. Solid-state lasers operating in the UV and visible spectral region have a lot of applications including laser lighting displays, photolithography, optical data storage, holography, microscopy, and spectroscopy. So far, there are three general methods to generate UV and visible laser emissions. One is using nonlinear frequency doubling or tripling processes. Another is developing short wavelength semiconductor laser diodes such as GaN and ZnSe. The third is employing upconversion emissions in fluoride glasses and crystals in which the nonradiative decay probabilities are relatively low due to the small phonon energy. Because the relatively long effective lifetimes of excited states facilitate a sequential absorption of pump photons either by a single ion or via energy transfer between excited ions, two or more incoming photons can be absorbed by the materials and can be reemitted as a single higher energy photon. Thus, UV and visible emission can be generated by pumping upconversion materials with high intensity pumps at near infrared.

Upconversion emission was observed for the first time in flash-lamp-pumped $\mathrm{Er}^{3+}-\mathrm{Yb}^{3+}$ and $\mathrm{Ho}^{3+}-\mathrm{Yb}^{3+}$ codoped $\mathrm{BaY}_{2} \mathrm{~F}_{8}$ crystals by Johnson and Guggenheim [122], who 


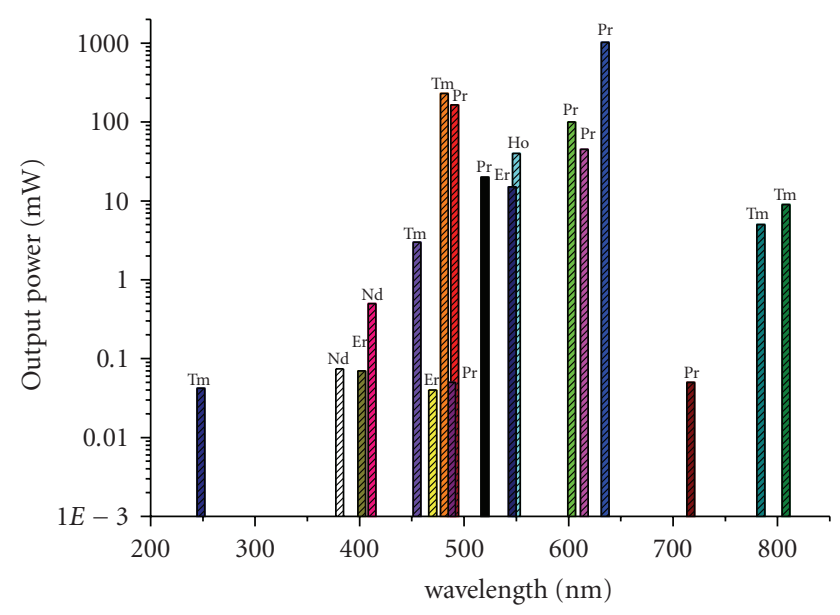

FIGURE 7: Highest output powers of upconversion rare-earth-doped ZBLAN fiber lasers at different emission wavelengths.

obtained stimulated emission at $670 \mathrm{~nm}$ and $551 \mathrm{~nm}$. Quimby et al. [123] reported infrared $(1.06 \mu \mathrm{m})$ to visible $(550 \mathrm{~nm})$ upconversion in a fluoride glass containing $\mathrm{Yb}^{3+}$ and $\mathrm{Er}^{3+}$ ions. Okada et al. [124] observed both red $(650 \mathrm{~nm})$ and green $(550 \mathrm{~nm})$ fluorescence from an $\mathrm{AlF}_{3}-\mathrm{ZrF}_{4}$-based glass containing $\mathrm{ErF}_{3}$ when pumped at an $807 \mathrm{~nm}$ laser diode. The two experiments on fluoride glasses suggested the feasibility of compact and efficient upconversion ZBLAN fiber lasers.

Upconversion ZBLAN fiber lasers are noted for their high efficiency, low threshold, compactness, and tenability. The confinement of both the pump and signal within the fiber core over the long distances reduces the pump threshold and increases output power significantly. High intensity coupled with the long interaction lengths results in optical-to-optical conversion efficiencies larger than $20 \%$ and threshold below $10 \mathrm{~mW}$. Moreover, because rare-earth-doped ZBLAN glasses exhibit broad absorption and emission spectral band, it is possible to construct all-fiber wavelength-tunable UV and visible fiber lasers.

In the past twenty years, various upconversion ZBLAN fiber lasers have been demonstrated at UV and visible. Output power over $1 \mathrm{~W}$ has already been achieved. The spectrum of upconversion ZBLAN fiber lasers with the highest output powers is summarized in Figure 7. Critical parameters of these fiber lasers are listed in Table 3. Progress of upconversion fiber lasers and their lasing mechanisms are described as follows.

3.2.1. Upconversion $\mathrm{Er}^{3+}$-Doped ZBLAN Fiber Lasers. The partial energy-level diagram of $\mathrm{Er}^{3+}$ ions to describe the transitions involving in upconversion emissions is plotted in Figure 8. When $\mathrm{Er}^{3+}$ ions are excited to higher energy levels via upconversion pumping, short wavelength emissions at $544 \mathrm{~nm}, 470 \mathrm{~nm}, 402 \mathrm{~nm}$, and $317 \mathrm{~nm}$ are possible via transitions from ${ }^{4} \mathrm{~S}_{3 / 2} \rightarrow{ }^{4} \mathrm{I}_{15 / 2},{ }^{2} \mathrm{P}_{3 / 2} \rightarrow{ }^{4} \mathrm{I}_{11 / 2},{ }^{2} \mathrm{P}_{3 / 2} \rightarrow$ ${ }^{4} \mathrm{I}_{13 / 2}$, and ${ }^{2} \mathrm{P}_{3 / 2} \rightarrow{ }^{4} \mathrm{I}_{15 / 2}$, respectively.

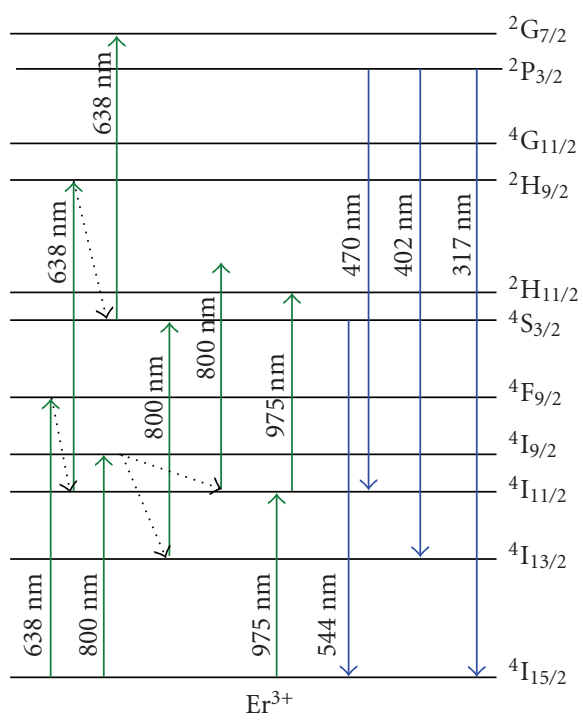

FIGURE 8: Partial energy level diagram of $\mathrm{Er}^{3+}$ ion in ZBLAN related to upconversion laser emissions. Pump absorption transitions are indicated with green upward arrows. Radiative transitions are indicated with blue downward arrows. Nonradiative decays are indicated with dotted arrows.

The first demonstration of upconversion lasing in an $\mathrm{Er}^{3+}$-doped ZBLAN fiber was realized using a pump at $801 \mathrm{~nm}$ of Ti:sapphire laser [138]. Maximum output of $23 \mathrm{~mW}$ CW emission at a wavelength of $546 \mathrm{~nm}$ has been achieved with a slope efficiency of $11 \%$. The dominant excitation mechanism is attributed to sequential ESA of pump photons. The $\mathrm{Er}^{3+}$ ions are excited into the ${ }^{4} \mathrm{I}_{9 / 2}$ level via GSA and some of which then branch into the ${ }^{4} \mathrm{I}_{11 / 2}$ and ${ }^{4} \mathrm{I}_{13 / 2}$ levels. These ions are then further excited by pump photons into the higher levels, from which a large proportion of the ions then relax into the ${ }^{4} S_{3 / 2}$ level. A direct transition ${ }^{4} S_{3 / 2} \rightarrow{ }^{4} \mathrm{I}_{15 / 2}$ is responsible for the green emission. However, a saturation behavior was observed in this experiment and was thought to be caused by competing laser transition ${ }^{4} \mathrm{~S}_{3 / 2} \rightarrow{ }^{4} \mathrm{I}_{13 / 2}$ at $850 \mathrm{~nm}$. Allain et al. [126] demonstrated a $50 \mathrm{~mW}$ tunable $(540 \mathrm{~nm}-545 \mathrm{~nm})$ green fiber laser in which the drawback of favoring oscillation of $850 \mathrm{~nm}$ was avoided by shifting the pump wavelength to $970 \mathrm{~nm}$. Pumping at $970 \mathrm{~nm}$ eliminates the competitive lasing because there is no ESA from ${ }^{4} \mathrm{I}_{13 / 2}$ at this wavelength. Diode-pumped green fiber lasers at 800 and $971 \mathrm{~nm}$ were demonstrated by Massicott et al. [139] and Piehler and Craven [140], respectively.

Aside from pumping at a wavelength of GSA, an upconversion laser can be excited with a wavelength far away from GSA due to the photon avalanche phenomenon which refers to the change in the order of magnitude of the fluorescence when the pump intensity is over a certain critical threshold. Chen et al. [141] demonstrated a roomtemperature photon avalanche up-conversion emission in an $\mathrm{Er}^{3+}$-doped ZBLAN fiber. A strong emission at $550 \mathrm{~nm}$ as well as a series of other wavelengths has been observed when the excitation wavelength is about $700 \mathrm{~nm}$. 
TABLE 3: Summary of upconversion rare-earth-doped ZBLAN fiber lasers with the highest output powers so far.

\begin{tabular}{|c|c|c|c|c|c|c|}
\hline Rare-earth & $\begin{array}{c}\text { Laser } \\
\text { Wavelength } \\
(\mathrm{nm})\end{array}$ & $\begin{array}{c}\text { Pump } \\
\text { Wavelength } \\
(\mathrm{nm})\end{array}$ & $\begin{array}{c}\text { Output } \\
\text { Power }(\mathrm{mW})\end{array}$ & $\begin{array}{c}\text { Rare-earth } \\
\text { Concentration } \\
(\mathrm{mol} \%)\end{array}$ & $\begin{array}{c}\text { Efficiency } \\
(\%)\end{array}$ & Reference \\
\hline \multirow{3}{*}{ Er } & 402 & 638 & 0.070 & 0.1 & 1.6 & {$[125]$} \\
\hline & 470 & 638 & 0.040 & 0.1 & 3 & {$[125]$} \\
\hline & 544 & 970 & 50 & 0.1 & 11 & {$[126]$} \\
\hline \multirow{5}{*}{$\mathrm{Tm}$} & 248 & 1064 & 0.042 & 1 & $9 \%$ & [127] \\
\hline & 455 & $645+1064$ & 3 & 0.1 & $1.5 \%$ & {$[128]$} \\
\hline & 481 & 1123 & 230 & 0.1 & $18.5 \%$ & [129] \\
\hline & 784 & 1120 & 5 & 0.1 & $0.7 \%$ & {$[130]$} \\
\hline & 808 & 1120 & 9 & 0.1 & $2.5 \%$ & {$[130]$} \\
\hline \multirow{5}{*}{$\mathrm{Pr} / \mathrm{Yb}$} & 491 & 840 & 165 & $0.3 / 2$ & 12.1 & {$[131]$} \\
\hline & 520 & 860 & 20 & $0.3 / 2$ & 12.4 & {$[132]$} \\
\hline & 605 & 840 & 55 & $0.3 / 2$ & 19 & [133] \\
\hline & 615 & 860 & 45 & $0.3 / 2$ & 11.5 & {$[132]$} \\
\hline & 635 & $850+823$ & 1020 & $0.3 / 2$ & 19 & [134] \\
\hline Ho & 550 & 645 & 40 & 0.12 & 16.8 & [135] \\
\hline \multirow{2}{*}{$\mathrm{Nd}$} & 381 & 590 & 0.074 & 0.1 & - & {$[136]$} \\
\hline & 412 & 590 & 0.5 & 0.1 & 1.5 & [137] \\
\hline
\end{tabular}

Generally, efficient shorter-wavelength emissions can be achieved if $\mathrm{Er}^{3+}$ ions are excited at a shorter pump wavelength. When the ZBLAN fiber is pumped with red lasers, $\mathrm{Er}^{3+}$ ions is excited to the ${ }^{4} \mathrm{~F}_{9 / 2}$ level and then relax to the ${ }^{4} \mathrm{I}_{11 / 2}$ and ${ }^{4} \mathrm{I}_{13 / 2}$ levels from which sequential ESA with pump photons results in populating on ${ }^{2} \mathrm{P}_{3 / 2}$ and ${ }^{4} \mathrm{~S}_{3 / 2}$ levels. Green, blue, and violet emissions can be achieved through the radiative decays from the ${ }^{4} \mathrm{~S}_{3 / 2}$ and ${ }^{2} \mathrm{P}_{3 / 2}$ levels [142]. Pope et al. [143] observed an efficient violet upconversion signal from an $\mathrm{Er}^{3+}$-doped ZBLAN fiber pumped at $633.5 \mathrm{~nm}$. Violet $402 \mathrm{~nm}$ and blue $470 \mathrm{~nm}$ upconversion-emission with power of several $10 \mu \mathrm{W}$ from $\mathrm{Er}^{3+}$-doped ZBLAN fibers have been obtained by Ferber et al. [125] using a laser diode at $638 \mathrm{~nm}$. In the energy upconversion and spectroscopic studies of $E r 3^{+}$-doped ZBLAN, Bullock et al. [144] pointed out that infrared to green, red to blue and violet, and blue to UV energy upconversion processes are able to occur by pumping the glass with different lasers. Most remarkably, when pumped at $488 \mathrm{~nm}$, UV emissions at $322 \mathrm{~nm}\left({ }^{2} \mathrm{I}_{11 / 2} \rightarrow\right.$ $\left.{ }^{4} \mathrm{I}_{11 / 2}\right), 352 \mathrm{~nm}\left({ }^{2} \mathrm{I}_{11 / 2} \rightarrow{ }^{4} \mathrm{I}_{9 / 2}\right), 275 \mathrm{~nm}\left({ }^{2} \mathrm{H}_{9 / 2} \rightarrow{ }^{4} \mathrm{I}_{15 / 2}\right)$, and $380 \mathrm{~nm}\left({ }^{2} \mathrm{H}_{9 / 2} \rightarrow{ }^{4} \mathrm{I}_{11 / 2}\right)$ were observed. This suggests that efficient UV emission can be achieved with tandem configurations, that is, using visible upconversion fiber lasers to pump UV upconversion lasers.

3.2.2. Upconversion $\mathrm{Tm}^{3+}$-Doped ZBLAN Fiber Lasers. The partial energy-level diagram of $\mathrm{Tm}^{3+}$ ions to describe the transitions involving in upconversion emissions is plotted in Figure 9. Usually visible and UV upconversion emissions at $515 \mathrm{~nm}, 480 \mathrm{~nm}, 455 \mathrm{~nm}, 365 \mathrm{~nm}, 350 \mathrm{~nm}$, and $284 \mathrm{~nm}$ can occur in a $\mathrm{Tm}^{3+}$-doped ZBLAN fiber through transition ${ }^{1} \mathrm{D}_{2} \rightarrow{ }^{3} \mathrm{H}_{5},{ }^{1} \mathrm{G}_{4} \rightarrow{ }^{3} \mathrm{H}_{6},{ }^{1} \mathrm{D}_{2} \rightarrow{ }^{3} \mathrm{~F}_{4},{ }^{1} \mathrm{D}_{2} \rightarrow{ }^{3} \mathrm{H}_{6}$, ${ }^{1} \mathrm{I}_{6} \rightarrow{ }^{3} \mathrm{~F}_{4}$, and, ${ }^{1} \mathrm{I}_{6} \rightarrow{ }^{3} \mathrm{H}_{6}$, respectively.

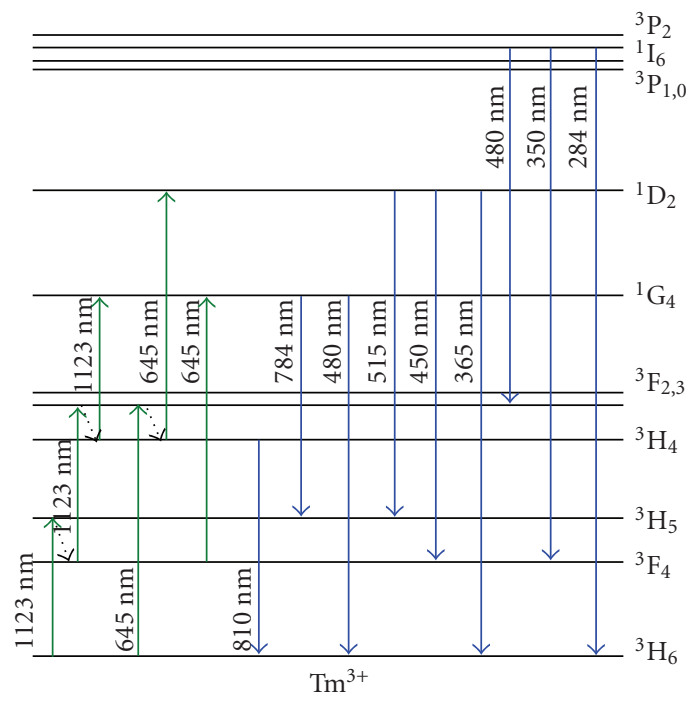

Figure 9: Partial energy level diagram of $\mathrm{Tm}^{3+}$ ion in ZBLAN related to upconversion laser emissions. Pump absorption transitions are indicated with green upward arrows. Radiative transitions are indicated with blue downward arrows. Nonradiative decays are indicated with dotted arrows.

In 1990, Allain et al. [145] demonstrated the first upconversion laser emission at $480 \mathrm{~nm}$ in a $\mathrm{Tm}^{3+}$-doped ZBLAN fiber copumped at $676.4 \mathrm{~nm}$ and $647.1 \mathrm{~nm} .676 .4 \mathrm{~nm}$ is used to populate the level ${ }^{3} \mathrm{H}_{4}$ by GSA and fast nonradiative decay processes since this wavelength is efficiently absorbed by levels ${ }^{3} \mathrm{~F}_{2}$ and ${ }^{3} \mathrm{~F}_{3} .647 .1 \mathrm{~nm}$ is used for ESA to populate the ${ }^{3} \mathrm{H}_{4}$ level and then the ${ }^{1} \mathrm{G}_{4}$ level. In the experiment, enhanced upconversion emissions at $365 \mathrm{~nm}, 455 \mathrm{~nm}, 480 \mathrm{~nm}$, and $515 \mathrm{~nm}$ were measured. Weak emissions at $288 \mathrm{~nm}$ and 
$350 \mathrm{~nm}$ have also been detected. However, the fiber was immersed in liquid nitrogen at $77 \mathrm{~K}$. The first singlewavelength pumped room temperature blue upconversion laser was demonstrated by Grubb et al. in 1992 [146]. The ${ }^{1} \mathrm{G}_{4}$ level is populated by three sequential absorptions of pump photons ${ }^{3} \mathrm{H}_{6} \rightarrow{ }^{3} \mathrm{H}_{5},{ }^{3} \mathrm{~F}_{4} \rightarrow{ }^{3} \mathrm{~F}_{2,3}$, and ${ }^{3} \mathrm{H}_{4} \rightarrow{ }^{1} \mathrm{G}_{4}$. $480 \mathrm{~nm}$ laser was obtained in $\mathrm{Tm}^{3+}$-doped ZBLAN glass fiber pumped by an $\mathrm{Nd}^{3+}$ :YAG laser at $1120 \mathrm{~nm}$. Up to $60 \mathrm{~mW}$ of output power has been measured with a slope efficiency of $18 \%$ with respect to coupled pump power. Infrared laser-diode-pumped $\mathrm{Tm}^{3+}$-doped ZBLAN fiber laser was demonstrated by Sanders et al. [147]. Maximum output of $106 \mathrm{~mW}$ with a conversion efficiency of 30\% was achieved by using two $600 \mathrm{~mW}$ laser diodes at $1137 \mathrm{~nm}$. In 1997, Zellmer et al. [148] demonstrated a $100 \mathrm{~mW}$ all fiber laser system in which a $\mathrm{Tm}^{3+} / \mathrm{Yb}^{3+}$-doped ZBLAN fiber was pumped with a $2.8 \mathrm{~W}$ diode pumped $\mathrm{Nd}^{3+}$-doped silica fiber laser at $1065 \mathrm{~nm}$. In the same year, Paschotta et al. [129] achieved the highest output $(230 \mathrm{~mW})$ of $480 \mathrm{~nm}$ light from a $\mathrm{Tm}^{3+}$-doped ZBLAN fiber laser pumped by a 1.6 W Nd:YAG laser at $1123 \mathrm{~nm}$. However, the fiber laser performance degraded quickly at high-power operation. It is believed that the excitation of higher levels of $\mathrm{Tm}^{3+}$ ions via energy transfer processes leads to the creation of color centers that significantly increase the absorption in visible band. Although a few investigations of photodegradation and photobleaching have been conducted [149-152], so far there still has no effective method to prevent photodegradation occurring in high-power operation of $\mathrm{Tm}^{3+}$-doped ZBLAN fiber lasers. Nevertheless, using new pumping schemes [153156] can improve the CW performance of $\mathrm{Tm}^{3+}$-doped ZBLAN fiber lasers by reducing the pump threshold and increasing the conversion efficiency. A pump threshold as low as $5 \mathrm{~mW}$ [155] was demonstrated by using pump sources at $1210 \mathrm{~nm}$ and $649 \mathrm{~nm}$ and a slope efficiency as high as $48 \%$ [156] has been achieved by using Raman-generated pumps at $1117 \mathrm{~nm}$ and $1175 \mathrm{~nm}$, respectively. Since $480 \mathrm{~nm} \mathrm{Tm}^{3+}$ doped ZBLAN fiber laser is a promising alternative for argon ion laser, a lot of theoretical studies [157-159] have also been carried out to help people understand and improve the performance of this fiber laser.

Another blue emission at $455 \mathrm{~nm}$ can be obtained from the transition ${ }^{1} \mathrm{D}_{2} \rightarrow{ }^{3} \mathrm{~F}_{4}$. The $455 \mathrm{~nm}$ radiation is selfterminated; therefore the lower laser level ${ }^{3} \mathrm{~F}_{4}$ is required to be emptied for achieving high-efficiency CW operation. Three different approaches can be utilized to solve the problem: (1) enforcing a cascade laser operation on the ${ }^{3} \mathrm{~F}_{4} \rightarrow{ }^{3} \mathrm{H}_{6}$ transition at $1.9 \mu \mathrm{m}$, (2) introducing crossrelaxation processes to relieve the ${ }^{3} \mathrm{~F}_{4}$ population efficiently by codoping with terbium or europium, and (3) pumping near $1.06 \mu \mathrm{m}$ in resonance with the ESA transition ${ }^{3} \mathrm{~F}_{4} \rightarrow$ ${ }^{3} \mathrm{~F}_{2,3}$. The first room-temperature $\mathrm{CW}$ upconversion laser at $455 \mathrm{~nm}$ in a $\mathrm{Tm}^{3+}$-doped ZBLAN fiber was demonstrated by Le Flohic et al. [128] using two pump sources at $645 \mathrm{~nm}$ and $1064 \mathrm{~nm}$. This pumping scheme populates the ${ }^{1} \mathrm{D}_{2}$ level and depopulates the ${ }^{3} \mathrm{H}_{4}$ level efficiently. As much as $3 \mathrm{~mW}$ of blue laser light has been obtained.

Aside from the blue band, upconversion emissions at other wavelengths have also been observed in $\mathrm{Tm}^{3+}$-doped

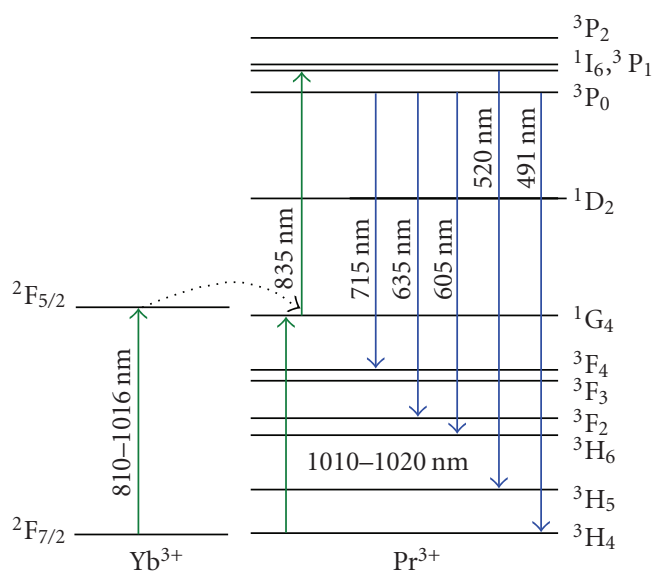

Figure 10: Partial energy level diagram of $\mathrm{Pr}^{3+}$ ion in ZBLAN related to upconversion laser emissions (Partial energy level diagram of $\mathrm{Yb}^{3+}$ ion is also plotted to indicate pump absorption and energy transfer from $\mathrm{Yb}^{3+}$ to $\mathrm{Pr}^{3+}$ ). Pump absorption transitions are indicated with green upward arrows. Radiative emission transitions are indicated with blue downward arrows.

ZBLAN fibers. Single wavelength $(784 \mathrm{~nm})$, two-wavelength $(785 \mathrm{~nm}+805 \mathrm{~nm}$ or $788 \mathrm{~nm}+793 \mathrm{~nm})$, three-wavelength $(787 \mathrm{~nm}+794 \mathrm{~nm}+802 \mathrm{~nm})$ upconversion laser has been demonstrated in a $\mathrm{Tm}^{3+}$-doped ZBLAN fiber pumped by a 1120 Raman fiber laser [130]. Ultraviolet upconversion signals at $293 \mathrm{~nm}\left({ }^{1} \mathrm{I}_{6} \rightarrow{ }^{3} \mathrm{H}_{6}\right), 351 \mathrm{~nm}\left({ }^{1} \mathrm{I}_{6} \rightarrow{ }^{3} \mathrm{~F}_{4}\right)$, and $366 \mathrm{~nm}\left({ }^{1} \mathrm{D}_{2} \rightarrow{ }^{3} \mathrm{H}_{6}\right)$ were observed from $\mathrm{Tm}^{3+}$ doped ZBLAN fiber pumped with an argon ion laser at $458 \mathrm{~nm}$ [160]. When the fiber was simultaneously pumped by $458 \mathrm{~nm}$ and $585 \mathrm{~nm}$ laser, enhanced upconversion signals at $293 \mathrm{~nm}$ and $351 \mathrm{~nm}$ were observed. Most recently, ElAgmy [127] demonstrated a successful CW ultraviolet laser operating at $284 \mathrm{~nm}$ in a $\mathrm{Tm}^{3+}$-doped ZBLAN fiber which was pumped with a $1064 \mathrm{~nm}$ Nd:YAG laser. A four-step upconversion pumping was involved in exciting $\mathrm{Tm}^{3+}$ ions to the upper laser level ${ }^{1} \mathrm{I}_{6}$. Due to the high $\mathrm{Tm}^{3+}$ concentration $(1 \mathrm{wt} \%)$, the favoring cross relaxation process ${ }^{1} \mathrm{G}_{4}+{ }^{1} \mathrm{G}_{4} \rightarrow$ ${ }^{1} \mathrm{I}_{6}+{ }^{3} \mathrm{~F}_{4}$ that populates the ${ }^{1} \mathrm{I}_{6}$ level and depletes the ${ }^{1} \mathrm{G}_{4}$ level enhances the ultraviolet emission. A laser output power of $42 \mu \mathrm{W}$ was obtained for $590 \mathrm{mw}$ of the launched pump power. The slope efficiency with respect to the launched pump power was measured to be $9 \%$.

\subsubsection{Upconversion $\mathrm{Pr}^{3+}$-Doped ZBLAN Fiber Lasers Upcon-} version. The partial energy-level diagram of $\operatorname{Pr}^{3+}$ ions to describe the transitions involving in the upconversion emissions is plotted in Figure 10. $\mathrm{Pr}^{3+}$-doped fluoride glass is notable for the white light fluorescence consisting of blue $(491 \mathrm{~nm})$, green $(520 \mathrm{~nm})$, orange $(605 \mathrm{~nm})$, red $(635 \mathrm{~nm})$, and infrared $(715 \mathrm{~nm})$ emission bands, which are resulted from radiative transitions ${ }^{3} \mathrm{P}_{0} \rightarrow{ }^{3} \mathrm{H}_{4},{ }^{3} \mathrm{P}_{1} \rightarrow{ }^{3} \mathrm{H}_{5},{ }^{3} \mathrm{P}_{0} \rightarrow$ ${ }^{3} \mathrm{H}_{6},{ }^{3} \mathrm{P}_{0} \rightarrow{ }^{3} \mathrm{~F}_{2}$, and ${ }^{3} \mathrm{P}_{0} \rightarrow{ }^{3} \mathrm{~F}_{4}$, respectively.

The first visible oscillation in $\mathrm{Pr}^{3+}$-doped ZBLAN fiber was demonstrated by Allain et al. [161]. Operation at orange and red wavelengths was achieved by pumping the fiber with an argon laser at $476.5 \mathrm{~nm}$. However, it was not upconversion 
lasing. Shortly after they obtained upconversion laser at $635 \mathrm{~nm}$ in a $\mathrm{Pr}^{3+} / \mathrm{Yb}^{3+}$-codoped ZBLAN fiber pumped by a Ti:sapphire laser at $850 \mathrm{~nm}$ [162]. The first upconversion lasing in a singly $\mathrm{Pr}^{3+}$-doped ZBLAN fiber was reported by Smart et al. [163, 164]. Laser oscillation at $491 \mathrm{~nm}$, $520 \mathrm{~nm}, 605 \mathrm{~nm}$, and $635 \mathrm{~nm}$ was realized by simultaneously pumping the fiber with two Ti:sapphire lasers at $1010 \mathrm{~nm}$ and $835 \mathrm{~nm}$. The top energy levels $\left({ }^{3} \mathrm{P}_{0},{ }^{1} \mathrm{I}_{6}\right.$, and $\left.{ }^{3} \mathrm{P}_{1}\right)$ are populated by a two-stage pumping: the GSA of $1010 \mathrm{~nm}$ light excites $\mathrm{Pr}^{3+}$ ions to an intermediate level ${ }^{1} \mathrm{G}_{4}$ and the ESA of $835 \mathrm{~nm}$ light further elevates excited $\mathrm{Pr}^{3+}$ ions to the top levels. An output of $185 \mathrm{~mW}$ has been measured for the $635 \mathrm{~nm}$ transition with an optical power conversion efficiency of approximate $7 \%$.

Using alternative pumping scheme can improve the performance of $\mathrm{Pr}^{3+}$-doped ZBLAN fiber and enhance the desired upconversion emission. When pumped at $835 \mathrm{~nm}$ and $1017 \mathrm{~nm}$, an efficient blue $\mathrm{Pr}^{3+}$-doped fluoride fiber upconversion laser operating at $492 \mathrm{~nm}$ was demonstrated with a slope efficiency of more than $13 \%$ and output power more than $9 \mathrm{~mW}$ [165]. Diode-pumped blue $\mathrm{Pr}^{3+}$-doped ZBLAN fiber laser was demonstrated by Baney [166] using two laser diodes at $830 \mathrm{~nm}$ and $1020 \mathrm{~nm}$. Because $492 \mathrm{~nm}$ is close to the wavelength of an argon ion laser, this pumping scheme has been further studied [167, 168]. Pask et al. [169] used a $\mathrm{Yb}^{3+}$-doped silica fiber laser pumped at $840 \mathrm{~nm}$ to provide two pump wavelengths, $840 \mathrm{~nm}$ and $1020 \mathrm{~nm}$ that are required for pumping a $\mathrm{Pr}^{3+}$-doped ZBLAN fiber upconversion laser. $54 \mathrm{~mW}$ output at $635 \mathrm{~nm}$ with a slope efficiency of $23 \%, 18 \mathrm{~mW}$ output at $520 \mathrm{~nm}$ with a slope efficiency of $8.5 \%$, and $7 \mathrm{~mW}$ output at $491 \mathrm{~nm}$ with a slope efficiency of $6 \%$ have been achieved.

For these singly $\mathrm{Pr}^{3+}$-doped ZBLAN fiber lasers, however, two pump lasers are required to excite $\operatorname{Pr}^{3+}$ ions to the upper laser level. In an effort to relieve the constraint of twowavelength pumping, $\mathrm{Yb}^{3+}$ ions was added as a sensitizer for $\mathrm{Pr}^{3+}$ upconversion emission because the broad absorption band of $\mathrm{Yb}^{3+}$ ions permits a wide pump wavelength, strong absorption of $\mathrm{Yb}^{3+}$ ions permits shorter length fiber that still yield adequate pump absorption, and the simple energy structure of $\mathrm{Yb}^{3+}$ ions reduces the possibility for backwards energy transfer from the activator ion.

The first upconversion laser operating at $635 \mathrm{~nm}$ was demonstrated in a $\mathrm{Pr}^{3+} / \mathrm{Yb}^{3+}$-codoped ZBLAN fiber pumped by a Ti:sapphire laser at $850 \mathrm{~nm}$ [162]. $\mathrm{Yb}^{3+}$ ions are excited by GSA and transfer energy to the ${ }^{1} \mathrm{G}_{4}$ level of $\mathrm{Pr}^{3+}$ ions, which is then brought into the ${ }^{3} \mathrm{P}_{0}$ upper laser level by ESA. Extracted powers in excess of $20 \mathrm{~mW}$ at $635 \mathrm{~nm}$ and a slope efficiency of $10 \%$ were measured. Xie and Gosnell [132] demonstrated room-temperature upconversion fiber laser tunable in the red, orange, green, and blue spectral regions in $\mathrm{Pr}^{3+} / \mathrm{Yb}^{3+}$ codoped ZBLAN fiber with a single Ti:sappire laser that can be tuned in the 780-880 $\mathrm{nm}$ wavelength region. Tunable laser operation over the $635 \mathrm{~nm}-637 \mathrm{~nm}, 605 \mathrm{~nm}-$ $622 \mathrm{~nm}, 517 \mathrm{~nm}-540 \mathrm{~nm}$, and $491 \mathrm{~nm}-493 \mathrm{~nm}$ wavelength bands was obtained. At a pump wavelength of $860 \mathrm{~nm}$, $300 \mathrm{~mW}$ output at $635 \mathrm{~nm}, 45 \mathrm{~mW}$ at $615 \mathrm{~nm}, 20 \mathrm{~mW}$ at $520 \mathrm{~nm}$, and $4 \mathrm{~mW}$ at $493 \mathrm{~nm}$ were measured. $\mathrm{Pr}^{3+} / \mathrm{Yb}^{3+}$ codoped ZBLAN fiber upconversion lasers pumped with a single semiconductor laser were reported by Baney et al. $[170,171]$. Red and orange or green and blue upconversion lasing was observed. Sandrock et al. [134] realized a highpower $\mathrm{CW}$ red radiation in a $\mathrm{Pr}^{3+} / \mathrm{Yb}^{3+}$-codoped ZBLAN fiber by tuning the wavelength of the Ti:sapphire pump laser to $850 \mathrm{~nm}$. A maximum output power of $675 \mathrm{~mW}$ was obtained at an incident pump power of $3.37 \mathrm{~W}$. When the fiber was pumped by two Ti:sapphire lasers at $852 \mathrm{~nm}$ and $826 \mathrm{~nm}$, the highest output at $635 \mathrm{~nm}(1020 \mathrm{~mW})$ so far was achieved. Using a 1.6 W Ti:sapphire laser as the pump source, Zellmer et al. [131] obtained more than $165 \mathrm{~mW}$ at $491 \mathrm{~nm}$ in a $\mathrm{Pr}^{3+} / \mathrm{Yb}^{3+}$-codoped ZBLAN fiber laser. Due to the high efficiency of $\mathrm{Pr}^{3+} / \mathrm{Yb}^{3+}$-codoped ZBLAN system, different fiber laser configurations such as actively mode-locked [172], all fiber tunable [133], and all-fiber ring [173] have also been constructed.

Goh et al. [174] demonstrate an alternative approach to achieve blue and red laser action in $\mathrm{Pr}^{3+}$-doped ZBLAN fiber using single-wavelength pump by sensitizing $\mathrm{Pr}^{3+}$ with $\mathrm{Nd}^{3+}$ ions which enable a strong absorption at $796 \mathrm{~nm} . \mathrm{Nd}^{3+}$ ions are excited to the ${ }^{2} \mathrm{D}_{5 / 2}$ level via upconversion pumping process. Nonradiative decay from the ${ }^{2} \mathrm{D}_{5 / 2}$ level populates the lower excited states ${ }^{4} \mathrm{G}_{11 / 2}$ and ${ }^{4} \mathrm{G}_{9 / 2}$, which are in close resonance with the ${ }^{1} \mathrm{I}_{6}$ and ${ }^{3} \mathrm{P}_{1}$ levels of $\mathrm{Pr}^{3+}$ ions. Energy transfer processes between $\mathrm{Nd}^{3+}$ and $\mathrm{Pr}^{3+}$ ions result in highly excited $\mathrm{Pr}^{3+}$ ions in the ${ }^{3} \mathrm{P}_{0},{ }^{3} \mathrm{P}_{1}$, and ${ }^{1} \mathrm{I}_{6}$ levels. Laser at blue $(488 \mathrm{~nm})$ and red $(635 \mathrm{~nm}, 717 \mathrm{~nm})$ has been observed in the $\mathrm{Pr}^{3+} / \mathrm{Nd}^{3+}$-codoped ZBLAN fiber laser with $796 \mathrm{~nm}$ pump.

3.2.4. Upconversion $\mathrm{Nd}^{3+}$-Doped ZBLAN Fiber Lasers. The partial energy-level diagram of $\mathrm{Nd}^{3+}$ ions to describe the transitions involving in upconversion emissions is plotted in Figure 11. When pumped at $590 \mathrm{~nm}, \mathrm{Nd}^{3+}$ ions are excited to the ${ }^{4} \mathrm{G}_{5 / 2}$ level via GSA and then decay to the ${ }^{4} \mathrm{~F}_{3 / 2}$ level, from which $\mathrm{Nd}^{3+}$ ions are excited to the upper laser levels by ESA. Radiative transition ${ }^{2} \mathrm{P}_{3 / 2} \rightarrow{ }^{4} \mathrm{I}_{11 / 2}$ produces emission at $412 \mathrm{~nm}$ and transition ${ }^{4} \mathrm{D}_{3 / 2} \rightarrow{ }^{4} \mathrm{I}_{11 / 2}$ produces emission at $381 \mathrm{~nm}$.

In 1994, Funk et al. [136] reported the first ultraviolet room-temperature $\mathrm{Nd}^{3+}$-doped ZBLAN fiber laser. Output power of $74 \mu \mathrm{W}$ at $381 \mathrm{~nm}$ was obtained with pumping with a $275 \mathrm{mw} 590 \mathrm{~nm}$ dye laser. One year later, a room temperature ZBLAN fiber laser in the violet band was demonstrated with the same experiment setup. Output power of $0.5 \mathrm{~mW}$ at $412 \mathrm{~nm}$ was produced for $320 \mathrm{~mW}$ of pump power at $590 \mathrm{~nm}$ [137].

3.2.5. Upconversion $\mathrm{Ho}^{3+}$-Doped ZBLAN Fiber Lasers. The partial energy-level diagram of $\mathrm{Ho}^{3+}$ ions to describe the transitions involving in the emission around $550 \mathrm{~nm}$ is plotted in Figure 12. $\mathrm{Ho}^{3+}$ ions are first excited to the intermediate ${ }^{5} \mathrm{~F}_{5}$ level via GSA ${ }^{5} \mathrm{I}_{8} \rightarrow{ }^{5} \mathrm{~F}_{5}$. The lower levels are then fed due to the fast nonradiative decay. $\mathrm{Ho}^{3+}$ ions in the metastable ${ }^{5} \mathrm{I}_{6}$ and ${ }^{5} \mathrm{I}_{7}$ levels are excited to higher levels via ESA and consequently populated the upper laser level ${ }^{5} \mathrm{~F}_{4}$. Radiative transition ${ }^{5} \mathrm{~F}_{4} \rightarrow{ }^{5} \mathrm{I}_{8}$ produces emission in the blue band. 


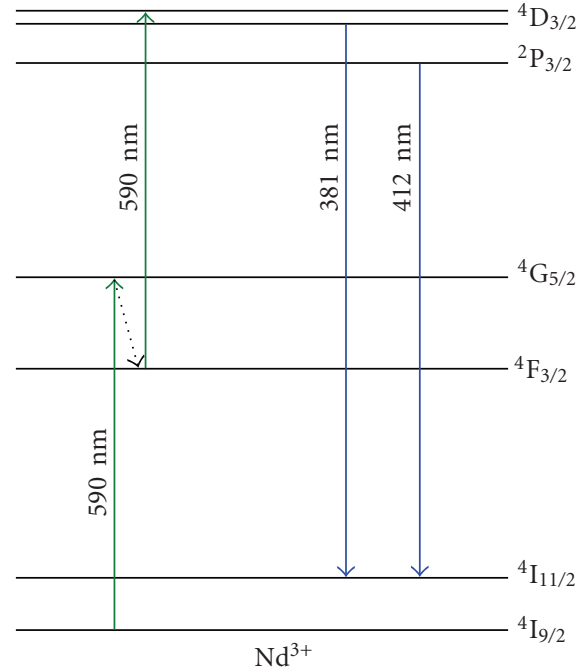

Figure 11: Partial energy level diagram of $\mathrm{Tm}^{3+}$ ion in ZBLAN related to upconversion laser emissions. Pump absorption transitions are indicated with green upward arrows. Radiative transitions are indicated with blue downward arrows. Nonradiative decays are indicated with dotted arrows.

In 1990, Allain et al. [175] reported a room-temperature CW tunable green upconversion $\mathrm{Ho}^{3+}$-doped ZBLAN fiber laser between $540 \mathrm{~nm}$ and $553 \mathrm{~nm}$ for the first time. The pump source was a krypton-ion laser at $647.1 \mathrm{~nm}$. Output powers in excess of $10 \mathrm{~mW}$ with slope efficiency of $20 \%$ were achieved. Diode-pumped $\mathrm{Ho}^{3+}$-doped ZBLAN fiber laser was demonstrated by Funk et al. [176] in 1997 using a $30 \mathrm{~mW}$ InGaAlP laser at $643 \mathrm{~nm}$. Excitation spectra, tunability, temporal and spectral characteristics of green $\mathrm{Ho}^{3+}$-doped ZBLAN fiber laser were investigated in detail by Funk et al. [177, 178]. In his continued experiment [135], power conversion efficiency, pump acceptance bandwidth, and excited-state kinetics were studied with a series of experiments in which the $\mathrm{Ho}^{3+}$-doped ZBLAN fiber laser has been characterized with regard to fiber length and core diameter, threshold pump power and slope efficiency, and pump acceptance bandwidth. The highest slope efficiency of $22 \%$, the maximum output power of $40 \mathrm{~mW}$, and an absorbed pump power threshold of less than $1 \mathrm{~mW}$ were obtained.

\subsection{Supercontinuum Generation Using ZBLAN Fibers. Super-} continuum generation is a physical process leading to dramatic spectral broadening of laser as it propagates through a nonlinear medium. Though the resulted beam has a very broad spectral bandwidth (i.e., low temporal coherence), its spatial coherence usually remains high. This particular property leads to extensive applications including coherence tomography, fluorescence microscopy, flow cytometry, optical devices characterization, dense wavelength division multiplexing in optical fiber communications systems, lightimaging detection and ranging, and optical frequency metrology.

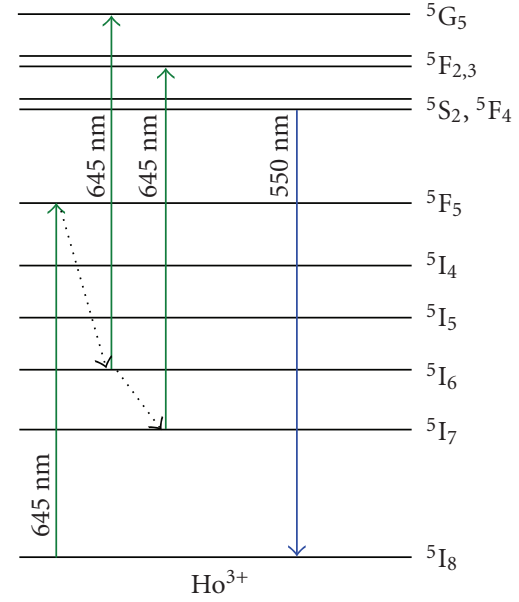

Figure 12: Partial energy level diagram of $\mathrm{Ho}^{3+}$ ion in ZBLAN related to upconversion laser emission in the blue band. Pump absorption transitions are indicated with green upward arrows. Radiative transition is indicated with blue downward arrow. Nonradiative decays are indicated with dotted arrows.

Since the first demonstration in bulk glass $[179,180]$, supercontinuum generation has been intensively investigated in a wide variety of nonlinear media including solids, organic and inorganic liquids, gases, and various types of waveguide. Optical fibers were suggested as a promising alternative for supercontinuum generation [181] because they can provide a significant length for nonlinear interaction. Especially, with the emergence of microstructured fibers [182] whose designs can be tailored to provide controllable dispersion and highly confined single-mode core, supercontinuum generation utilizing optical fibers has drawn tremendous interest in the past ten years. However, most of the investigations were carried out on silica fibers and the long wave edge of supercontinuum is limited to $\sim 2 \mu \mathrm{m}$, the multiphonon edge of silica glass. As continuum at mid-infrared wavelength region is of much interest, ZBLAN fiber is a preferred media due to its low background loss and wide transparency window.

The first supercontinuum generation in ZBLAN fiber was demonstrated by Hagen et al. [183]. A commercial modelocked $\mathrm{Er}^{3+}$-doped fiber laser at $1550 \mathrm{~nm}$ with an energy of $1.5 \mu \mathrm{J}$ per pulse, a duration of 900 femtosecond, and a repetition of $200 \mathrm{kHz}$ was used to pump a $21-\mathrm{cm}$ long standard single-mode silica fiber that was connected by a $91 \mathrm{~cm}$ long common ZBLAN fiber with a core diameter $8.5 \mathrm{um}$ and a NA of 0.21 . By cascaded Raman soliton selfshifting, a continuum extending to a wavelength of $\sim 3 \mu \mathrm{m}$ was generated. The total average power emitted in the $1.8 \mu \mathrm{m}-3.4 \mu \mathrm{m}$ range is $5 \mathrm{~mW}$. The average spectral power is $\sim 4 \mu \mathrm{W} / \mathrm{nm}$ at the range of $1.4 \mu \mathrm{m}-2.9 \mu \mathrm{m}$.

Using a similar fiber construction, Xia et al. [184] demonstrated an alternative approach to generate supercontinuum beyond $4.5 \mu \mathrm{m}$ from a ZBLAN fiber pumped by amplified nanosecond laser diode pulses. The supercontinuum generation is initiated by the breakup of nanosecond 
laser diode pulses into femtosecond pulses through modulation instability, and the spectrum is then broadened primarily through self-phase modulation and stimulated Raman scattering in the following ZBLAN fiber. A supercontinuum with a spectrum from $0.8 \mu \mathrm{m}$ to $4.5 \mu \mathrm{m}$, an average power of $23 \mathrm{~mW}$, and a spectral power density of $-20 \mathrm{dBm} / \mathrm{nm}$ was achieved. In contrast to femtosecond pulse, nanosecond pulse can be readily amplified by multiple stages of fiber amplifiers. Therefore, using nanosecond pulse to generate supercontinuum is more scalable with recent advances of high-power fiber amplifiers. The average power of the supercontinuum was scaled up to 1.3 watts when a threestage fiber amplifier was used [185] and up to 10.5 watts when a more powerful power amplifier was used [186, 187]. However, the short wave edge is limited to $0.8 \mu \mathrm{m}$ and the plug-in efficiency is still low due to the small efficiency of erbium fiber amplifiers at $1.55 \mu \mathrm{m}$. The two problems may be solved by pumping ZBLAN fiber with $1 \mu \mathrm{m}$ laser. Recently, when a $2.5-\mathrm{cm}$-long fluoride fiber was pumped by a $1450 \mathrm{~nm}$ femtosecond laser, supercontinuum from 0.35 $\mu \mathrm{m}$ to $3.85 \mu \mathrm{m}$ was generated [188]. However, all these supercontina mentioned above are temporally incoherent. A method to generate coherent mid-infrared broadband continuum in nonuniform ZBLAN fiber taper was proposed [189]. It is believed that high efficiency and high-power supercontinuum covering a spectral region from $0.2 \mu \mathrm{m}$ to $4.5 \mu \mathrm{m}$ or a longer wavelength will emerge in the near future considering recent progress of high-power $1 \mu \mathrm{m}$ fiber laser and amplifiers and microstructured ZBLAN fibers [190]. It should be noted that other soft-glass fibers with high nonlinearities [191-193] have also been demonstrated and proposed to generate ultra-broad supercontinuum. Though ZBLAN glass has the nonlinearity even less than that of silica glass, ZBLAN fibers are superior to other soft-glass fibers for high-power supercontinuum generation due to their much lower background loss and relatively higher strength.

\section{Discussion and Prospect}

With the advent of reliable and high-brightness diode pump lasers and double-clad fibers that facilitate coupling the highly elliptical pump light into the fiber, output power of single-mode fiber laser has been significantly increased over the past decade. Output power of $6 \mathrm{~kW}$ has been successfully demonstrated in the $\mathrm{Yb}^{3+}$-doped single-mode silica fiber [5]. Now ZBLAN fiber lasers can provide $>20 \mathrm{~W}$ output at mid-infrared [16]. Evolutions of $\mathrm{Yb}^{3+}$-doped silica and $\mathrm{Er}^{3+}$-doped ZBLAN fiber lasers are illustrated in Figure 13. Although fragility and low transition temperature restrict the extractable output of ZBLAN fiber lasers, there are still some space for power scaling and output power over 100 watts is possible.

Basically, nonlinear phenomena such as stimulated Raman scattering (SRS) and stimulated Brillouin scattering (SBS), thermal effects, and optical damage are major constraints on power scaling of CW fiber lasers. SRS and SBS resulting from stimulated inelastic scattering processes transfer a part of the energy of the incident light to the glass

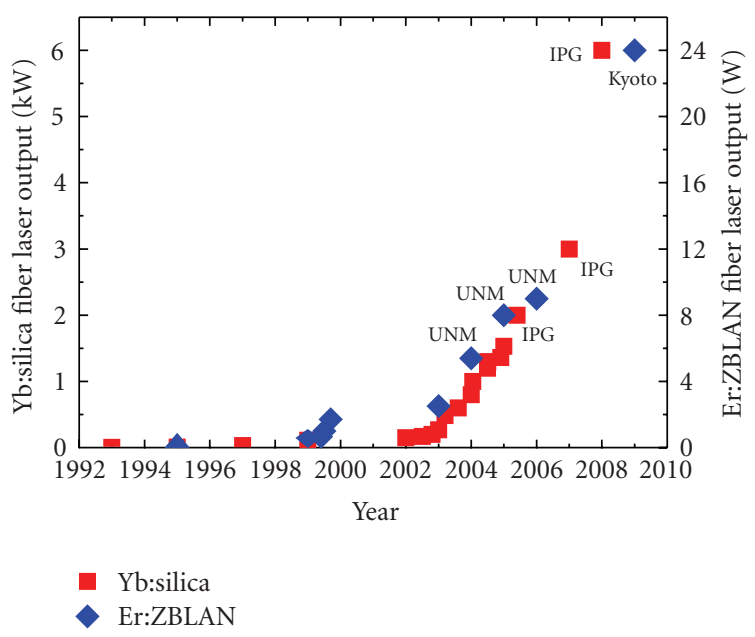

FIGURE 13: Evolution of continuous-wave output of single-mode $1 \mu \mathrm{m}$ silica fiber laser and $2.7 \mu \mathrm{m}$ ZBLAN fiber laser over the past decade.

host in the form of excited vibrational modes and red-shift the wavelength of the light. Both processes lead to significant power loss and deteriorate the performance of high-power fiber lasers. Though the chief advantage of fiber lasers over bulk solid-state lasers is their outstanding heat-dissipation capability due to the large ratio of surface area to volume of the fiber allowing effective heat dissipation with minimal heat-sinking requirements, heat generation during a very high-power operation can still destroy an optical fiber, via thermal damage of the coating, fracture, or even melting of the core. Due to the occurrence of self pulsing, optically induced damage is also a hindrance of power scaling of fiber lasers [14]. Generally, for silica fiber lasers, nonlinearity limits the performance of the fiber systems before limits due to thermal effects or fracture of the fiber are reached. For ZBLAN fiber lasers, however, thermal effects and optical damage always happen at a power level much lower than that for the occurrence of nonlinear phenomena due to the low transition temperature $\left(\sim 260^{\circ} \mathrm{C}\right)$ and the fragility of ZBLAN glass. Therefore, avoiding optical damage and reliving thermal effects are two routes to beak through the power limits of ZBLAN fiber lasers.

Self-pulsing has been frequently observed in high-power fiber lasers $[14,15,194]$. It can be induced by relaxed oscillation, saturated absorption effect, SRS, and SBS. The pulses caused by these instabilities carry sufficient optical energy to cause catastrophic damage to the fiber facets. The damage threshold of rare-earth-doped ZBLAN glass is about $25 \mathrm{MW} / \mathrm{cm}^{2}$ as measured by using $10-\mathrm{ms}$ long pulses at $2.8 \mu \mathrm{m}$ [14]. The damage threshold of ZBLAN fiber with respect to the core diameter is plotted in Figure 14. Large-mode-area fiber can effectively increase the extractable power of a ZBLAN fiber laser. It is also found that dualend pumping configuration can effectively suppress the selfpulsing in ZBLAN fiber lasers [194].

With recent ZBLAN fiber technology, sing-mode infrared fiber with a core diameter of tens of microns can be fabricated 


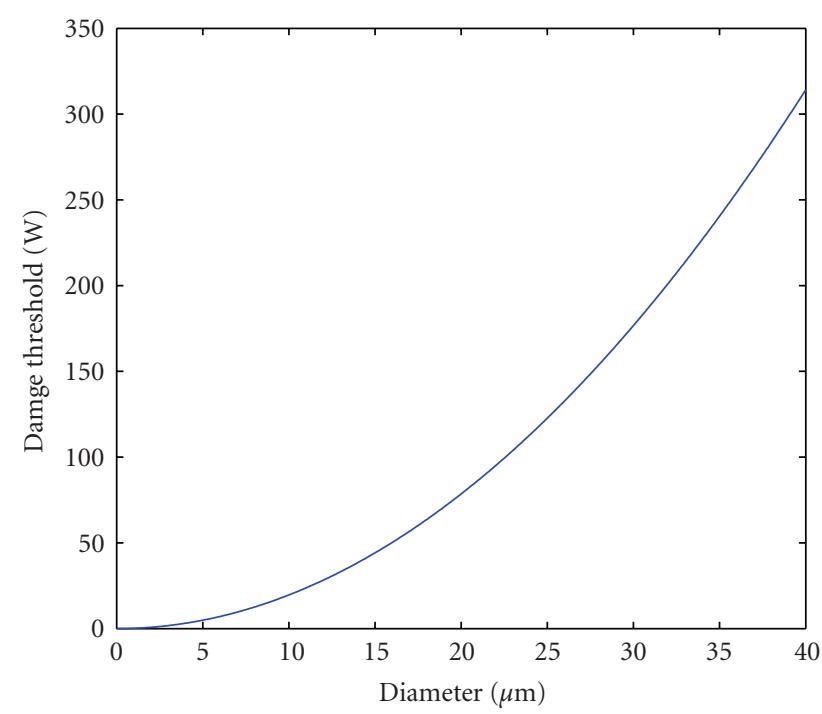

Figure 14: Optical damage threshold of a ZBLAN fiber with respective to its core diameter.

and thereby is capable of delivering tens of or even over 100 watts output. However, as the core size increases, thermal effects are enhanced and actively cooling is required for efficient heat dissipation. For a common rare-earth-doped fiber, the temperature distribution in the core and the cladding region can be calculated by the following equations [195]:

$$
\begin{aligned}
T_{\text {core }}(r)= & T_{c}+\frac{Q_{0} a^{2}}{4 k}\left[2 \ln \left(\frac{b}{a}\right)+\frac{2 k}{b h}\right] \\
& +\frac{Q_{0} a^{2}}{4 k}\left[1-\left(\frac{r}{a}\right)^{2}\right], \\
T_{\text {cladding }}(r)= & T_{c}+\frac{Q_{0} a^{2}}{2 b h}-\frac{Q_{0} a^{2}}{2 k} \ln \left(\frac{r}{b}\right),
\end{aligned}
$$

where $T_{c}$ is the coolant temperature, $Q_{0}$ is the heat power density, $k$ is the thermal conductivity, $h$ is the convective heat transfer coefficient, $a$ and $b$ are the radii of the core and the cladding, respectively. For the actively cooled $\mathrm{Er}^{3+}$ doped ZBLAN fiber laser described in [14] pumped with a $100 \mathrm{~W}$ laser diode at $975 \mathrm{~nm}$, the temperature distribution at the pumped fiber facet is plotted in Figure 15. The fiber core center has the highest temperature. Therefore, in order to ensure the stable performance of a fiber laser, effective cooling is required to keep the core center temperature much smaller than the transition temperature of ZBLAN glass $\left(\sim 260^{\circ} \mathrm{C}\right)$. Moreover, the spatial variation in temperature can lead to internal stresses within the fiber and result in ultimately catastrophic failure as a fracture when the thermally induced stress exceeds the tensile strength. High efficiency heat dissipation is also necessary to avoid large temperature variation. The distribution of the core center temperature along the fiber is plotted in Figure 16. The pumping end has the highest temperature and the temperature decreases with the reduced absorbed pump to the minimum value at the other end, thereby the pumping end needs more efficient

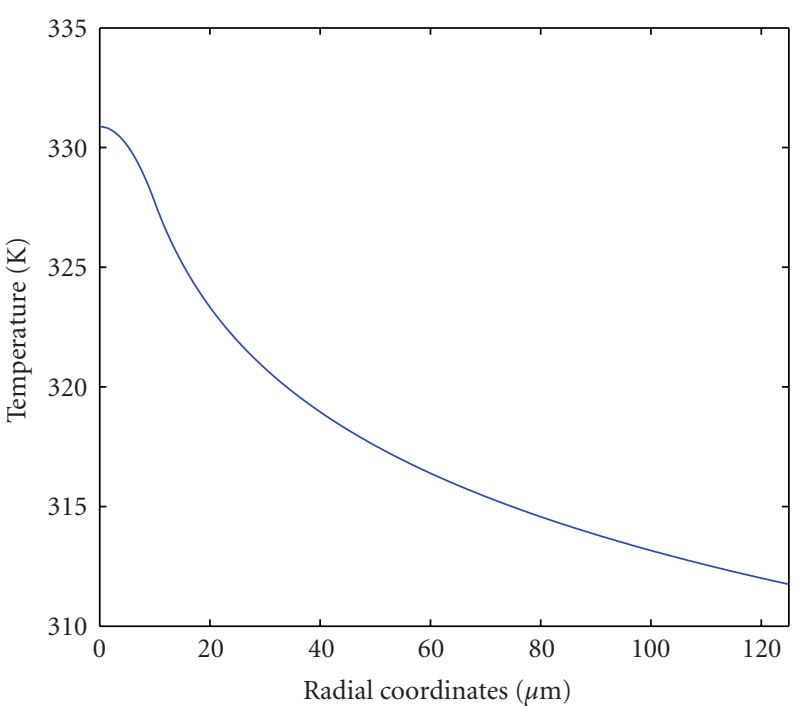

FIGURE 15: Temperature in the pumping end of the $\mathrm{Er}^{3+}$-doped ZBLAN fiber as a function of radial coordinates for a $100 \mathrm{~W} 975 \mathrm{~nm}$ pump.

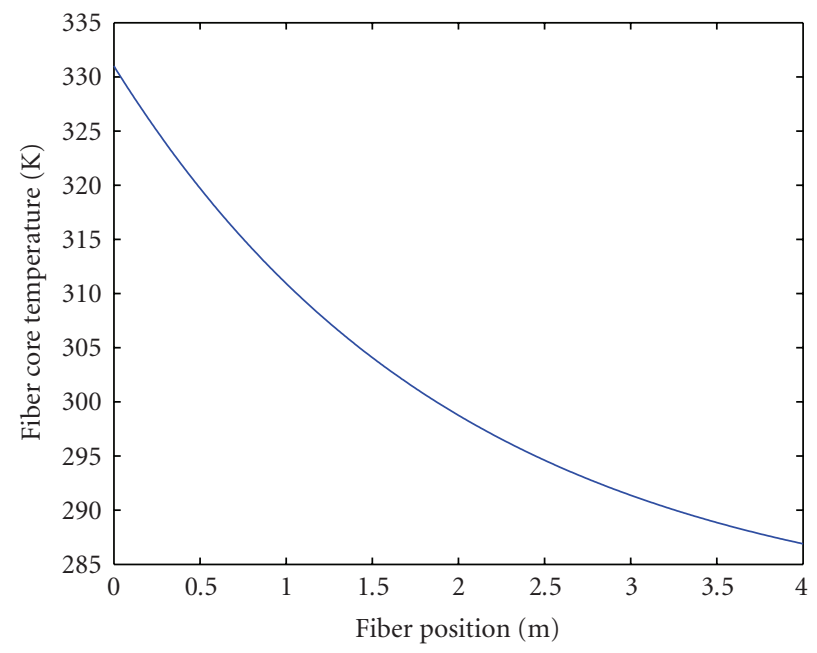

FIGURE 16: Core center temperature in the $\mathrm{Er}^{3+}$-doped ZBLAN fiber as a function of fiber position for a $100 \mathrm{~W} 975 \mathrm{~nm}$ pump.

heat dissipation. The core center temperature of the pumping end as a function of the heat transfer coefficient is shown in Figure 17. When the pumping end is not actively cooled $(h<$ $100)$, the core temperature largely exceeds the melt point of ZBLAN glass and consequently the fiber will be readily melt down. Therefore, sufficient cooling is crucial for high-power ZBLAN fiber lasers. For instance, in the $24 \mathrm{~W}$ diode-pumped $\mathrm{Er}^{3+}$-doped ZBLAN fiber laser, a liquid-cooling system was utilized to efficiently remove the heat [16].

Aside from optical damage and thermal effects, photodarkening, a phenomenon with significant increase of the core absorption at visible and near-infrared wavelengths when the fiber is pumped with high-power infrared light, also need to be taken into account for high-power upconversion ZBLAN fiber lasers. In 1995, Barber [196] observed 


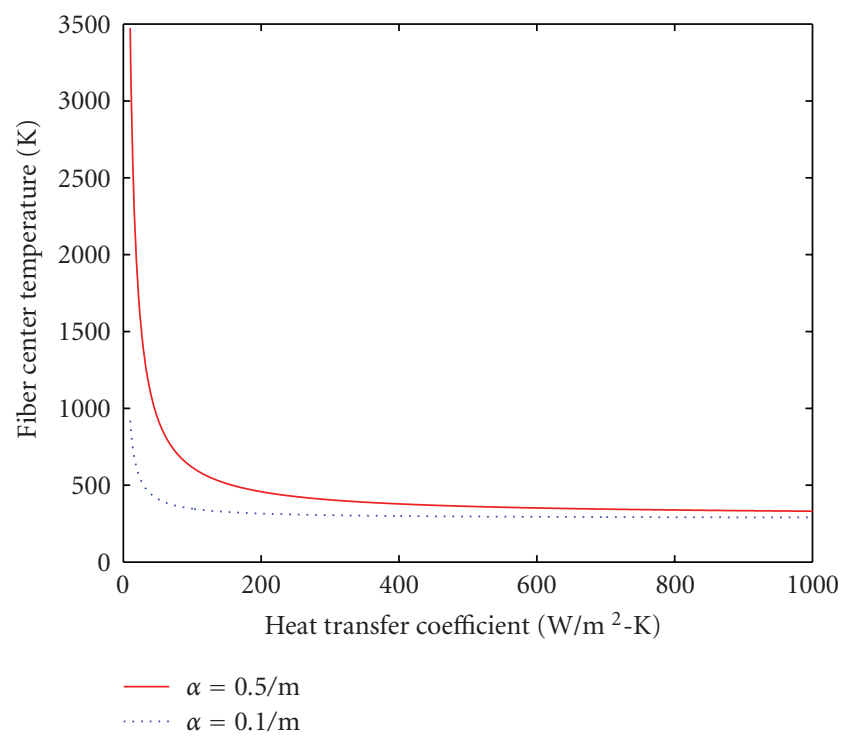

FIGURE 17: Core center temperature in the $\mathrm{Er}^{3+}$-doped ZBLAN fiber as a function of heat transfer coefficient for a $100 \mathrm{~W} 975 \mathrm{~nm}$ pump ( $\alpha$ is the absorption coefficient).

a phenomenon of infrared-induced photodarkening in $\mathrm{Tm}^{3+}$-doped fluoride fibers for the first time. The loss induced in the visible region by $1140 \mathrm{~nm}$ radiation is very strong (as high as $25 \mathrm{~dB}$ in a $50 \mathrm{~cm}$ piece) and broadband. Laperle et al. [149] found that the darkening rate is shown to follow a fourth-power dependence on the pumping intensity and a strong dependence on the $\mathrm{Tm}^{3+}$ ion concentration. The photodegradation of upconversion $\mathrm{Tm}^{3+}$-doped ZBLAN fiber lasers was also observed [150]. After upconversion lasing at $482 \mathrm{~nm}$, the fiber absorbs strongly at wavelength below $650 \mathrm{~nm}$ affecting further upconversion lasing. The physical details of photodarkening are very complicated and have so far not been fully understood. The formation of color centers or other microscopic structural transformations in the fiber core would be the main cause. Since photodarkening can lead to serious performance degradations of upconversion fiber lasers, it would be particularly important to fully understand the mechanisms and minimize the effect to a large extent by optimizing the compositions of ZBLAN glass and the laser operation conditions.

On the other hand, a fiber laser can produce more output power with less heat generation when the efficiency of optical conversion is increased. Using pump with a wavelength close to the desire laser wavelength can increase the conversion efficiency and reduce the heat generation accordingly. Upconversion energy transfer and cross-relaxation processes between ions in high-concentration fibers can be used for efficiency improvement due to the doubled quantum efficiency. Cascade lasing is also an effective method to enhance the desired laser emission and reduce the heat generation by replacing the nonradiative multiphonon process with radiative emission. For upconversion fiber lasers, proper pumping scheme can also increase the efficiency and effectively avoid nonradiative transitions.
It should be mentioned here that Bragg gratings can be directly inscribed on the ZBLAN fibers with femtosecond pulses now [197, 198]. This enables the construction of a ZBLAN fiber laser in a monolithic all-fiber configuration $[51,102]$. Narrow line-width mid-IR sources which can be used for spectroscopic sensing can also benefit from the convenient writing of ZBLAN fiber Bragg grating.

Following the development of high-power silica fiber lasers, performance of ZBLAN fiber lasers can be further improved and 100-watt-level output is possible with largecore ZBLAN fibers or beam combining techniques [199] in the near future. Due to the increasing demand of laser sources at wavelengths where silica fiber lasers cannot operate, high-power ZBLAN fiber lasers covering from ultraviolet to mid-infrared are promising for further development in the next decade.

\section{Summary}

Fluoride glass properties and ZBLAN fiber fabrication are introduced briefly in this paper to give readers a general knowledge of this remarkable gain medium. Detailed progress of infrared, upconversion UV and visible, and supercontinuum ZBLAN fiber lasers were reviewed. Optical damage, thermal effects, and photodarkening are the three major constraints on power scaling of ZBLAN fiber lasers. Using novel fiber design and high-brightness diode pumps, output power of $>20 \mathrm{~W}$ has recently been obtained by sufficiently cooling the ZBLAN fiber laser system. In the next decade, a variety of high-power ZBLAN fiber lasers covering from ultraviolet to mid-infrared will emerge.

\section{References}

[1] T. H. Maiman, "Stimulated optical radiation in ruby," Nature, vol. 187, no. 4736, pp. 493-494, 1960.

[2] H. E. Labelle, "EFG, the invention and application to sapphire growth," Journal of Crystal Growth, vol. 50, pp. 87, 1980.

[3] A. El Hassouni, K. Lebbou, C. Goutaudier, G. Boulon, A. Yoshikawa, and T. Fukuda, "SBN single crystal fibers grown by micro-pulling down technique," Optical Materials, vol. 24, no. 1-2, pp. 419-424, 2003.

[4] Y. Ji, S. Zhao, Y. Huo, H. Zhang, M. Li, and C. Huang, "Growth of lithium triborate (LBO) single crystal fiber by the laser-heated pedestal growth method," Journal of Crystal Growth, vol. 112, no. 1, pp. 283-286, 1991.

[5] V. P. Gapontsev, "High power fiber laser and it's application," in Proceedings of the 4th International Symposium on HighPower Fiber Lasers and Their Applications, St. Petersburg, Russia, June 2008.

[6] T. Qiu, L. Li, A. Schülzgen, et al., "Generation of 9.3-W multimode and 4-W single-mode output from 7-cm short fiber lasers," IEEE Photonics Technology Letters, vol. 16, no. 12, pp. 2592-2594, 2004.

[7] A. Schülzgen, L. Li, V. L. Temyanko, S. Suzuki, J. V. Moloney, and N. Peyghambarian, "Single-frequency fiber oscillator with watt-level output power using photonic crystal phosphate glass fiber," Optics Express, vol. 14, no. 16, pp. 70877092, 2006. 
[8] R. E. Slusher, G. Lenz, J. Hodelin, J. Sanghera, L. B. Shaw, and I. D. Aggarwal, "Large Raman gain and nonlinear phase shifts in high-purity $\mathrm{As}_{2} \mathrm{Se}_{3}$ chalcogenide fibers," Journal of the Optical Society of America B, vol. 21, no. 6, pp. 1146-1155, 2004.

[9] J. S. Sanghera, I. D. Aggarwal, L. B. Shaw, et al., "Nonlinear properties of chalcogenide glass fibers," Journal of Optoelectronics and Advanced Materials, vol. 8, no. 6, pp. 2148-2155, 2006.

[10] T. Schweizer, B. N. Samson, R. C. Moore, D. W. Hewak, and D. N. Payne, "Rare-earth doped chalcogenide glass fibre laser," Electronics Letters, vol. 33, no. 5, pp. 414-416, 1997.

[11] A. Mori, Y. Ohishi, T. Kanamori, and S. Sudo, "Optical amplification with neodymium-doped chalcogenide glass fiber," Applied Physics Letters, vol. 70, no. 10, pp. 1230-1232, 1997.

[12] L. B. Shaw, B. Cole, P. A. Thielen, J. S. Sanghera, and I. D. Aggarwal, "Mid-wave IR and long-wave IR laser potential of rare-earth doped chalcogenide glass fiber," IEEE Journal of Quantum Electronics, vol. 37, no. 9, pp. 1127-1137, 2001.

[13] R. S. Quimby, L. B. Shaw, J. S. Sanghera, and I. D. Aggarwal, "Modeling of cascade lasing in Dy: chalcogenide glass fiber laser with efficient output at $4.5 \mu \mathrm{m}$," IEEE Photonics Technology Letters, vol. 20, pp. 123-125, 2008.

[14] X. Zhu and R. Jain, "10-W-level diode-pumped compact $2.78 \mu \mathrm{m}$ ZBLAN fiber laser," Optics Letters, vol. 32, no. 1, pp. 26-28, 2007.

[15] M. Eichhorn and S. D. Jackson, "Comparative study of continuous wave $\mathrm{Tm}^{3+}$-doped silica and fluoride fiber lasers," Applied Physics B, vol. 90, no. 1, pp. 35-41, 2008.

[16] S. Tokita, M. Murakami, S. Shimizu, M. Hashida, and S. Sakabe, "Liquid-cooled $24 \mathrm{~W}$ mid-infrared Er:ZBLAN fiber laser," Optics Letters, vol. 34, no. 20, pp. 3062-3064, 2009.

[17] Y. Miyajima, T. Komukai, T. Sugawa, and T. Yamamoto, "Rare earth-doped fluoride fiber amplifiers and fiber lasers," Optical Fiber Technology, vol. 1, no. 1, pp. 35-47, 1994.

[18] D. S. Funk and J. G. Eden, "Glass-fiber lasers in the ultraviolet and visible," IEEE Journal on Selected Topics in Quantum Electronics, vol. 1, no. 3, pp. 784-791, 1995.

[19] K. Ohsawa and T. Shibata, "preparation and characterization of $\mathrm{ZrF}_{4}-\mathrm{BaF}_{2}-\mathrm{LaF}_{3}-\mathrm{NaF}_{-} \mathrm{AlF}_{3}$ glass optical fibers," Journal of Lightwave Technology, vol. 2, no. 5, pp. 602-606, 1984.

[20] P. W. France, S. F. Carter, C. R. Day, and M. W. Moore, Optical Properties and Applications in Fluoride Glasses, John Wiley \& Sons, Hoboken, NJ, USA, 1989.

[21] A. Comyns, Fluoride Glasses, John Wiley \& Sons, Chichester, UK, 1989.

[22] J. M. Parker, "Fluoride glasses," Annual Review of Materials Science, vol. 19, pp. 21-41, 1989.

[23] P. Klocek and G. H. Sigel, Infrared Fiber Optics, SPIE, Bellingham, Wash, USA, 1989.

[24] P. France, M. G. Drexhage, J. M. Parker, M. W. Moore, S. F. Carter, and J. V. Wright, Fluoride Glass Optical Fibers, Blackie and Son, London, UK, 1990.

[25] I. Aggarwal and G. Lu, Fluoride Glass Fiber Optics, Academic Press, Boston, Mass, USA, 1991.

[26] F. Gan, "Optical properties of fluoride glasses: a review," Journal of Non-Crystalline Solids, vol. 184, no. 1, pp. 9-20, 1995.

[27] J. S. Sanghera, L. E. Busse, I. D. Aggarwal, and C. F. Rapp, Infrared Fiber Optics, CRC Press, Boca Raton, Fla, USA, 1998.

[28] J. A. Hamrrington, Infrared Fibers and Their Applications, SPIE, Bellingham, Wash, USA, 2004.
[29] M. Poulain, M. Poulain, and J. Lucas, "Verres fluores au tetrafluorure de zirconium proprietes optiques d'un verre dope au Nd $\mathrm{Nd}^{3+}$, Materials Research Bulletin, vol. 10, no. 4, pp. 243-246, 1975.

[30] K. Ohsawa, T. Shibata, K. Nakamura, and S. Yoshida, "Fluorozirconate glasses for infrared transmitting optical fibers," in Proceedings of the 7th European Conference on Optical Communication (ECOC), pp. 1.1-1-1.1-4, Copenhagen, Danmark, September 1981.

[31] T. Kanamori and S. Sakaguchi, "Preparation of elevated NA fluoride optical fibers," Japanese Journal of Applied Physics, vol. 25, no. 6, pp. L468-L470, 1986.

[32] S. Mitachi and T. Manabe, "Fluoride glass fiber for infrared transmission," Japanese Journal of Applied Physics, vol. 20, pp. L313-L314, 1980.

[33] S. Mitachi, T. Miyashita, and T. Kanamori, "Fluoride-glasscladded optical fibers for mid-infra-red ray transmission," Electronics Letters, vol. 17, no. 17, pp. 591-592, 1981.

[34] S. Mitachi, T. Miyashita, and T. Manabe, "Preparation of fluoride optical fibers for transmission in the mid-infrared," Physics and Chemistry of Glasses, vol. 23, no. 6, pp. 196-201, 1982.

[35] D. C. Tran, C. F. Fisher, and G. H. Sigel Jr., "Fluoride glass performs prepared by a rotation casting process," Electronics Letters, vol. 18, pp. 657-658, 1982.

[36] H. Tokiwa, Y. Mimura, T. Nakai, and O. Shinbori, "Fabrication of long single-mode and multimode fluoride glass fibers by the double-crucible technique," Electronics Letters, vol. 21, no. 24, pp. 1131-1132, 1985.

[37] J. Lucas, M. Chanthanasinh, M. Poulain, M. Poulain, P. Brun, and M. J. Weber, "Preparation and optical properties of neodymium fluorozirconate glasses," Journal of NonCrystalline Solids, vol. 27, no. 2, pp. 273-283, 1978.

[38] M. C. Brierley and P. W. France, "Neodymium-doped fluorozirconate fiber laser," Electronics Letters, vol. 23, no. 16, pp. 815-817, 1987.

[39] M. C. Brierley, P. W. France, M. W. Moore, and S. T. Davey, "Rare-earth-doped fluorozirconate fiber lasers," in Conference on Lasers and Electro-Optics (CLEO), Anaheim, Calif, USA, 1988, V7, TUM29.

[40] W. J. Miniscalco, L. J. Andrews, B. A. Thompson, R. S Quimby, L. J. B. Vacha, and M. G. Drexhage, "1.3 $\mu$ m fluoride fiber laser,” Electronics Letters, vol. 24, no. 1, pp. 28-29, 1988.

[41] M. C. Brierley and C. A. Millar, "Amplification and lasing at $1350 \mathrm{~nm}$ in a neodymium doped fluorozirconate fibre," Electronics Letters, vol. 24, no. 7, pp. 438-439, 1988.

[42] L. Wetenkamp, "Efficient CW operation of a $2.9 \mu \mathrm{m} \mathrm{Ho}{ }^{3+}$ doped fluorozirconate fibre laser pumped at $640 \mathrm{~nm}$," Electronics Letters, vol. 26, no. 13, pp. 883-884, 1990.

[43] C. Carbonnier, H. Tobben, and U. B. Unrau, "Room temperature CW fibre laser at $3.22 \mu \mathrm{m}$," Electronics Letters, vol. 34, no. 9, pp. 893-894, 1998.

[44] J. Schneider, "Fluoride fibre laser operating at $3.9 \mu \mathrm{m}$," Electronics Letters, vol. 31, no. 15, pp. 1250-1251, 1995.

[45] M. C. Brierley and P. W. France, "Continuous wave lasing at $2.7 \mu \mathrm{m}$ in an erbium-doped fluorozirconate fiber," Electronics Letters, vol. 24, no. 15, pp. 935-937, 1988.

[46] Toebben, "CW lasing at $3.45 \mu \mathrm{m}$ in erbium-doped fluorozirconate fibres," Frequenz, vol. 45, no. 9-10, pp. 250-252, 1991.

[47] H. Toebben, "Room temperature CW fibre laser at $3.5 \mu \mathrm{m}$ in $\mathrm{Er}^{3+}$-doped ZBLAN glass," Electronics Letters, vol. 28, no. 14, pp. 1361-1362, 1992. 
[48] R. Allen and L. Esterowitz, "CW diode pumped $2.3 \mu \mathrm{m}$ fiber laser," Applied Physics Letters, vol. 55, no. 8, pp. 721-722, 1989.

[49] Z. Meng, J. Kamebayashi, M. Higashihata, et al., "1.55- $\mu \mathrm{m}$ Ce-Er-ZBLAN fiber laser operation under 980 -nm pumping: experiment and simulation," IEEE Photonics Technology Letters, vol. 14, no. 5, pp. 609-611, 2002.

[50] C. Ghisler, M. Pollnau, G. Bunea, M. Bunea, W. Luthy, and H. P. Weber, "Up-conversion cascade laser at $1.7 \mu$ with simultaneous $2.7 \mu \mathrm{m}$ lasing in erbium ZBLAN fibre," Electronics Letters, vol. 31, no. 5, pp. 373-374, 1995.

[51] G. Androz, M. Bernier, D. Faucher, and R. Vallee, " $2.3 \mathrm{~W}$ single transverse mode thulium-doped ZBLAN fiber laser at 1480 nm," Optics Express, vol. 16, no. 20, pp. 16019-16031, 2008.

[52] S. D. Jackson, " $8.8 \mathrm{~W}$ diode-cladding-pumped $\mathrm{Tm}^{3+}, \mathrm{Ho}^{3+}$ doped fluoride fibre laser," Electronics Letters, vol. 37, no. 13, pp. 821-822, 2001

[53] S. D. Jackson, "Single-transverse-mode 2.5-W holmiumdoped fluoride fiber laser operating at $2.86 \mu \mathrm{m}$," Optics Letters, vol. 29, no. 4, pp. 334-336, 2004.

[54] J. Schneider, C. Carbonnier, and U. B. Unrau, "Characterization of $\mathrm{a} \mathrm{Ho}^{3+}$-doped fluoride fiber laser with a 3.9- $\mu \mathrm{m}$ emission wavelength," Applied Optics, vol. 36, no. 33, pp. 8595-8600, 1997.

[55] S. D. Jackson, "Continuous wave $2.9 \mu \mathrm{m}$ dysprosium-doped fluoride fiber laser," Applied Physics Letters, vol. 83, no. 7, pp. 1316-1318, 2003.

[56] Y. Durteste, M. Monerie, J. Y. Allain, and H. Poignant, "Amplification and lasing at $1.3 \mu \mathrm{m}$ in praseodymium-doped fluorozirconate fibres," Electronics Letters, vol. 27, no. 8, pp. 626-628, 1991.

[57] J. Y. Allain, M. Monerie, and H. Poignant, "Ytterbium-doped fluoride fibre laser operating at $1.02 \mu \mathrm{m}$," Electronics Letters, vol. 28, no. 11, pp. 988-989, 1992.

[58] T. Komukai, Y. Fukasaku, T. Sugawa, and Y. Miyajima, "Highly efficient and tunable $\mathrm{Nd}^{3+}$ doped fluoride fibre laser operating in $1.3 \mu \mathrm{m}$ band," Electronics Letters, vol. 29, no. 9, pp. 755-756, 1993.

[59] N. J. Vasa, S. Nagaoka, T. Okada, Y. Kubota, N. Nishimura, and T. Teshima, "Widely tunable Ce- and Er-codoped fluorozirconate fiber laser with 975-nm laser diode pumping," IEEE Photonics Technology Letters, vol. 17, no. 4, pp. 759-761, 2005.

[60] M. Pollnau, Ch. Ghisler, W. Luthy, H. P. Weber, J. Schneider, and U. B. Unrau, "Three-transition cascade erbium laser at 1.7, 2.7, and 1.6 $\mu \mathrm{m}$," Optics Letters, vol. 22, no. 9, pp. 612$614,1997$.

[61] J. Schneider, "Mid-infrared fluoride fiber lasers in multiple cascade operation," IEEE Photonics Technology Letters, vol. 7, no. 4, pp. 354-356, 1995.

[62] R. G. Smart, J. N. Carter, D. C. Hanna, and A. C. Tropper, "Erbium doped fluorozirconate fibre laser operating at 1.66 and $1.72 \mu \mathrm{m}$," Electronics Letters, vol. 26, no. 10, pp. 649-651, 1990.

[63] L. Esterowitz, R. Allen, G. Kintz, L. Aggarwal, and R. J. Ginther, "Laser emission in $\mathrm{Tm}^{3+}, \mathrm{Er}^{3+}$ doped fluorozirconate glass at $2.55,1.88$, and $2.70 \mu \mathrm{m}$," in Proceedings of the Conference on Laser and Electro-Optics (CLEO), pp. 318-320, Anaheim, Calif, USA, 1988.

[64] J. Y. Allain, M. Monerie, and H. Poignant, "Erbiumdoped fluorozirconate single-mode fibre lasing at $2.71 \mu \mathrm{m}$," Electronics Letters, vol. 25, no. 1, pp. 28-29, 1989.
[65] H. Yanagita, I. Masuda, T. Yamashita, and H. Toratani, "Diode laser pumped $\mathrm{Er}^{3+}$ fibre laser operation between 2.7$2.8 \mu \mathrm{m}$," Electronics Letters, vol. 26, no. 22, pp. 1836-1838, 1990.

[66] R. Allen, L. Esterowitz, and R. J. Ginther, "Diode-pumped single-mode fluorozirconate fiber laser from the ${ }^{4} \mathrm{I}_{11 / 2} \rightarrow$ ${ }^{4} \mathrm{I}_{13 / 2}$ transition in erbium," Applied Physics Letters, vol. 56, no. 17, pp. 1635-1637, 1990.

[67] Ch. Frerichs, "Efficient $\mathrm{Er}^{3+}$-doped CW fluorozirconate fiber laser operating at $2.7 \mu \mathrm{m}$ pumped at $980 \mathrm{~nm}$," International Journal of Infrared and Millimeter Waves, vol. 15, no. 4, pp. 635-649, 1994.

[68] J. Schneider, D. Hauschild, Ch. Frerichs, and L. Wetenkamp, "Highly efficient $\mathrm{Er}^{3+}$ : $\mathrm{Pr}^{3+}$-codoped CW fluorozirconate fiber laser operating at $2.7 \mu \mathrm{m}$," International Journal of Infrared and Millimeter Waves, vol. 15, no. 11, pp. 1907-1922, 1994.

[69] S. Bedo, M. Pollnau, W. Luthy, and H. P. Weber, "Saturation of the $2.71 \mu \mathrm{m}$ laser output in erbium-doped ZBLAN fibers," Optics Communications, vol. 116, no. 1-3, pp. 81-86, 1995.

[70] S. Bedo, W. Luthy, and H. P. Weber, "Limits of the output power in $\mathrm{Er}^{3+}$ :ZBLAN singlemode fibre lasers," Electronics Letters, vol. 31, no. 3, pp. 199-200, 1995.

[71] M. Pollnau, Ch. Ghisler, G. Bunea, M. Bunea, W. Luthy, and H. P. Weber, " $150 \mathrm{~mW}$ unsaturated output power at $3 \mu \mathrm{m}$ from a single-mode-fiber erbium cascade laser," Applied Physics Letters, vol. 66, no. 26, pp. 3564-3566, 1995.

[72] S. D. Jackson, "High-power erbium cascade fibre laser," Electronics Letters, vol. 45, no. 16, pp. 830-832, 2009.

[73] M. Pollnau, R. Spring, Ch. Ghisler, S. Wittwer, W. Luthy, and H. P. Weber, "Efficiency of erbium $3-\mu \mathrm{m}$ crystal and fiber lasers," IEEE Journal of Quantum Electronics, vol. 32, no. 4, pp. 657-663, 1996.

[74] E. Poppe, B. Srinivasan, and R. K. Jain, "980 nm diodepumped continuous wave mid-IR $(2.7 \mu \mathrm{m})$ fibre laser," Electronics Letters, vol. 34, no. 24, pp. 2331-2333, 1998.

[75] B. Srinivasan, E. Poppe, J. Tafoya, and R. K. Jain, "Highpower $(400 \mathrm{~mW})$ diode-pumped $2.7 \mu \mathrm{m}$ Er:ZBLAN fibre lasers using enhanced Er-Er cross-relaxation processes," Electronics Letters, vol. 35, no. 16, pp. 1338-1340, 1999.

[76] B. Srinivasan, J. Tafoya, and R. K. Jain, "High-power "Watt-level" CW operation of diode-pumped $2.7 \mu \mathrm{m}$ fiber lasers using efficient cross-relaxation and energy transfer mechanisms," Optics Express, vol. 4, no. 12, pp. 490-495, 1999.

[77] S. D. Jackson, T. A. King, and M. Pollnau, "Diode-pumped 1.7-W erbium 3- $\mu \mathrm{m}$ fiber laser," Optics Letters, vol. 24, no. 16, pp. 1133-1135, 1999.

[78] T. Sandrock, D. Fischer, P. Glas, M. Leitner, M. Wrage, and A. Diening, "Diode-pumped 1-W Er-doped fluoride glass Mprofile fiber laser emitting at $2.8 \mu \mathrm{m}$," Optics Letters, vol. 24, no. 18, pp. 1284-1286, 1999.

[79] P. S. Golding, S. D. Jackson, T. A. King, and M. Pollnau, "Energy transfer processes in $\mathrm{Er}^{3+}$-doped and $\mathrm{Er}^{3+}, \mathrm{Pr}^{3+}$ codoped ZBLAN glasses," Physical Review B, vol. 62, no. 2, pp. 856-864, 2000.

[80] S. D. Jackson, T. A. King, and M. Pollnau, "Efficient high power operation of erbium $3 \mu \mathrm{m}$ fibre laser diode-pumped at 975 nm," Electronics Letters, vol. 36, no. 3, pp. 223-224, 2000.

[81] S. D. Jackson, T. A. King, and M. Pollnau, "Modelling of highpower diode-pumped erbium $3 \mu \mathrm{m}$ fibre lasers," Journal of Modern Optics, vol. 47, no. 11, pp. 1987-1994, 2000. 
[82] N. J. C. Libatique, J. Tafoya, N. K. Viswanathan, R. K. Jain, and A. Cable, "Field-usable' diode-pumped $120 \mathrm{~nm}$ wavelength-tunable CW mid-IR fibre laser," Electronics Letters, vol. 36, no. 9, pp. 791-792, 2000.

[83] V. K. Bogdanov, D. J. Booth, W. E. K. Gibbs, J. S. Javorniczky, P. J. Newman, and D. R. MacFarlane, "Population dynamics in $\mathrm{Er}^{3+}$-doped fluoride glasses," Physical Review B, vol. 63, no. 20, Article ID 205107, 15 pages, 2001.

[84] M. Pollnau and S. D. Jackson, "Erbium 3- $\mu \mathrm{m}$ fiber lasers," IEEE Journal on Selected Topics in Quantum Electronics, vol. 7, no. 1, pp. 30-40, 2001.

[85] M. Pollnau and S. D. Jackson, "Energy recycling versus lifetime quenching in erbium-doped 3- $\mu \mathrm{m}$ fiber lasers," IEEE Journal of Quantum Electronics, vol. 38, no. 2, pp. 162-169, 2002.

[86] D. J. Coleman, T. A. King, D.-K. Ko, and J. Lee, "Q-switched operation of a $2.7 \mu \mathrm{m}$ cladding-pumped $\mathrm{Er}^{3+} / \mathrm{Pr}^{3+}$ codoped ZBLAN fibre laser," Optics Communications, vol. 236, no. 46, pp. 379-385, 2004.

[87] X. Zhu and R. Jain, "Numerical analysts and experimental results of high-power Er/Pr:ZBLAN $2.7 \mu \mathrm{m}$ fiber lasers with different pumping designs," Applied Optics, vol. 45, no. 27, pp. 7118-7125, 2006.

[88] X. Zhu and R. Jain, "Compact $2 \mathrm{~W}$ wavelength-tunable Er:ZBLAN mid-infrared fiber laser," Optics Letters, vol. 32, no. 16, pp. 2381-2383, 2007.

[89] X. Zhu and R. Jain, "Watt-level 100-nm tunable 3- $\mu$ m fiber laser," IEEE Photonics Technology Letters, vol. 20, no. 2, pp. 156-158, 2008.

[90] X. Zhu and R. Jain, "Watt-level Er-doped and Er-Pr-codoped ZBLAN fiber amplifiers at the 2.7-2.8 $\mu \mathrm{m}$ avelength range," Optics Letters, vol. 33, no. 14, pp. 1578-1580, 2008.

[91] M. Bernier, D. Faucher, N. Caron, and R. Vallee, "Highly stable and efficient erbium-doped $2.8 \mu \mathrm{m}$ all fiber laser," Optics Express, vol. 17, no. 19, pp. 16941-16946, 2009.

[92] D. S. Tucker, E. C. Ethridge, G. A. Smith, and G. Workman, "Effects of gravity on ZBLAN glass crystallization," Annals of the New York Academy of Sciences, vol. 1027, pp. 129-137, 2004.

[93] J. Y. Allain, M. Monerie, and H. Poignant, "Tunable CW lasing around $0.82,1.48,1.88$ and $2.35 \mu \mathrm{m}$ in thulium-doped fluorozirconate fibre," Electronics Letters, vol. 25, no. 24, pp. 1660-1662, 1989.

[94] R. M. Percival, D. Szebesta, and S. T. Davey, "Highly efficient CW cascade operation of 1.47 and $1.82 \mu \mathrm{m}$ transitions in Tmdoped fluoride fibre laser," Electronics Letters, vol. 28, no. 20, pp. 1866-1868, 1992.

[95] R. Allen, L. Esterowitz, and I. Aggarwal, "Efficient $1.46 \mu \mathrm{m}$ thulium fiber laser via a cascade process," IEEE Journal of Quantum Electronics, vol. 29, no. 2, pp. 303-306, 1993.

[96] R. M. Percival, D. Szebesta, and S. T. Davey, "Thulium doped terbium sensitized CW fluoride fibre laser operating on the $1.47 \mu \mathrm{m}$ transition," Electronics Letters, vol. 29, no. 12, pp. 1054-1056, 1993.

[97] T. Komukai, T. Yamamoto, T. Sugawa, and Y. Miyajima, "Efficient upconversion pumping at $1.064 \mu \mathrm{m}$ of $\mathrm{Tm}^{3+}$-doped fluoride fibre laser operating around $1.47 \mu \mathrm{m}$," Electronics Letters, vol. 28, no. 9, pp. 830-832, 1992.

[98] R. M. Percival, D. Szebesta, and J. R. Williams, "Highly efficient $1.064 \mu \mathrm{m}$ upconversion pumped $1.47 \mu \mathrm{m}$ thulium doped fluoride fibre laser," Electronics Letters, vol. 30, no. 13, pp. 1057-1058, 1994.
[99] T. Komukai, T. Yamamoto, T. Sugawa, and Y. Miyajima, "Upconversion pumped thulium-doped fluoride fiber amplifier and laser operating at $1.47 \mu \mathrm{m}$," IEEE Journal of Quantum Electronics, vol. 31, no. 11, pp. 1880-1889, 1995.

[100] Y. Miyajima, T. Komukai, and T. Sugawa, "1-W CW Tmdoped fluoride fibre laser at $1.47 \mu \mathrm{m}$," Electronics Letters, vol. 29, no. 8, pp. 660-661, 1993.

[101] R. M. El-Agmy, W. Luthy, Th. Graf, and H. P. Weber, "1.47 $\mu \mathrm{m} \mathrm{Tm}{ }^{3+}$ :ZBLAN fibre laser pumped at $1.064 \mu \mathrm{m}$," Electronics Letters, vol. 39, no. 6, pp. 507-508, 2003.

[102] G. Androz, D. Faucher, M. Bernier, and R. Vallee, "Monolithic fluoride-fiber laser at $1480 \mathrm{~nm}$ using fiber Bragg gratings," Optics Letters, vol. 32, no. 10, pp. 1302-1304, 2007.

[103] R. M. Percival, S. F. Carter, D. Szebesta, S. T. Davey, and W. A. Stallard, "Thulium-doped monomode fluoride fibre laser broadly tunable from 2.25 to $2.5 \mu \mathrm{m}$," Electronics Letters, vol. 27, no. 21, pp. 1912-1913, 1991.

[104] M. C. Brierley, P. W. France, and C. A. Millar, "Lasing at $2.08 \mu \mathrm{m}$ and $1.38 \mu \mathrm{m}$ in a holmium doped fluorozirconate fiber laser," Electronics Letters, vol. 24, no. 9, pp. 539-540, 1988.

[105] R. M. Percival, D. Szebesta, S. T. Davey, N. A. Swain, and T. A. King, "High-efficiency CW operation of $890 \mathrm{~nm}$ pumped holmium fluoride fibre laser," Electronics Letters, vol. 28, no. 22, pp. 2064-2066, 1992.

[106] J. Y. Allain, M. Monerie, and H. Poignant, "High-efficiency CW thulium-sensitised holmium-doped fluoride fibre laser operating at $2.04 \mu \mathrm{m}$," Electronics Letters, vol. 27, no. 17, pp. 1513-1515, 1991.

[107] L. Wetenkamp, "Efficient CW operation of a $2.9 \mu \mathrm{m} \mathrm{Ho}{ }^{3+}$ doped fluorozirconate fibre laser pumped at $640 \mathrm{~nm}$," Electronics Letters, vol. 26, no. 13, pp. 883-884, 1990.

[108] T. Sumiyoshi and H. Sekita, "Dual-wavelength continuouswave cascade oscillation at 3 and $2 \mu \mathrm{m}$ with a holmiumdoped fluoride-glass fiber laser," Optics Letters, vol. 23, no. 23, pp. 1837-1839, 1998.

[109] T. Sumiyoshi, H. Sekita, T. Arai, S. Sato, M. Ishihara, and M. Kikuchi, "High-power continuous-wave 3- and 2- $\mu$ m cascade $\mathrm{Ho}^{3+}$ :ZBLAN fiber laser and its medical applications," IEEE Journal on Selected Topics in Quantum Electronics, vol. 5, no. 4, pp. 936-943, 1999.

[110] S. D. Jackson, "Singly $\mathrm{Ho}^{3+}$-doped fluoride fibre laser operating at $2.92 \mu \mathrm{m}$," Electronics Letters, vol. 40, no. 22, pp. 1400-1401, 2004.

[111] F. Z. Qamar, T. A. King, S. D. Jackson, and Y. H. Tsang, "Holmium, praseodymium-doped fluoride fiber laser operating near $2.87 \mu \mathrm{m}$ and pumped with a Nd:YAG laser," Journal of Lightwave Technology, vol. 23, no. 12, pp. 43154320, 2005.

[112] S. D. Jackson, F. Bugge, and G. Erbert, "Directly diodepumped holmium fiber lasers," Optics Letters, vol. 32, no. 17, pp. 2496-2498, 2007.

[113] S. D. Jackson, "High-power and highly efficient diodecladdingpumped holmium-doped fluoride fiber laser operating at $2.94 \mu \mathrm{m}$," Optics Letters, vol. 34, no. 15, pp. 2327-2329, 2009.

[114] S. D. Jackson, "Singly $\mathrm{Ho}^{3+}$-doped fluoride fibre laser operating at $2.92 \mu \mathrm{m}$," Electronics Letters, vol. 40, no. 22, pp. 1400-1401, 2004.

[115] D. V. Talavera and E. B. Mejia, "Holmium-doped fluoride fiber laser at $2950 \mathrm{~nm}$ pumped at $1175 \mathrm{~nm}$," Laser Physics, vol. 16, no. 3, pp. 436-440, 2006. 
[116] H. Tobben, Neue faserlaser für das nahe und mittlere infrarot, dissertation, Technische Universität Braunschweig, Braunschweig, Germany, 1993.

[117] Y. H. Tsang, A. E. El-Taher, T. A. King, and S. D. Jackson, "Efficient $2.96 \mu \mathrm{m}$ dysprosium-doped fluoride fibre laser pumped with a Nd:YAG laser operating at $1.3 \mu \mathrm{m}$," Optics Express, vol. 14, no. 2, pp. 678-685, 2006.

[118] W. J. Miniscalco, L. J. Andrews, B. A. Thompson, R. S Quimby, L. J. B. Vacha, and M. G. Drexhage, " $1.3 \mu \mathrm{m}$ fluoride fiber laser," Electronics Letters, vol. 24, no. 1, pp. 28-29, 1988.

[119] D. C. Hanna, R. M. Percival, I. R. Perry, R. G. Smart, and A. C. Tropper, "Efficient operation of an Yb-sensitised Er fibre laser pumped in $0.8 \mu \mathrm{m}$ region," Electronics Letters, vol. 24, no. 17, pp. 1068-1069, 1988.

[120] T. Sugawa, E. Yoshida, Y. Miyajima, and M. Nakazawa, "1.6 ps Pulse generation from a $1.3 \mu \mathrm{m} \mathrm{Pr}^{3+}$-doped fluoride fibre laser," Electronics Letters, vol. 29, no. 10, pp. 902-903, 1993.

[121] M. J. Guy, D. U. Noske, A. Boskovic, and J. R. Taylor, "Femtosecond soliton generation in a praseodymium fluoride fiber lasers," Optics Letters, vol. 19, no. 11, pp. 828-830, 1994.

[122] L. F. Johnson and H. J. Guggenheim, "Infrared-pumped visible laser," Applied Physics Letters, vol. 19, no. 2, pp. 44-47, 1971.

[123] R. S. Quimby, M. G. Drexhage, and M. J. Suscavage, "Efficient frequency up-conversion via energy transfer in fluoride glasses," Electronics Letters, vol. 23, no. 1, pp. 32-34, 1987.

[124] K. Okada, K. Miura, I. Masuda, and T. Yamashita, "Upconversion fluorescences in $\mathrm{AlF}_{3}-\mathrm{ZrF}_{4}$ based fluoride glass containing $\mathrm{ErF}_{3}$," Materials Science Forum, vol. 32-33, pp. 523-528, 1988.

[125] S. Ferber, V. Gaebler, and H.-J. Eichler, "Violet and blue upconversion-emission from erbium-doped ZBLAN-fibers with red diode laser pumping," Optical Materials, vol. 20, no. 3, pp. 211-215, 2002.

[126] J. Y. Allain, M. Monerie, and H. Poignant, "Tunable green upconversion erbium fibre laser," Electronics Letters, vol. 28, no. 2, pp. 111-113, 1992.

[127] R. M. El-Agmy, "Upconversion CW laser at $284 \mathrm{~nm}$ in a Nd:YAG-pumped double-cladding thulium-doped ZBLAN fiber laser," Laser Physics, vol. 18, no. 6, pp. 803-806, 2008.

[128] M. P. Le Flohic, J. Y. Allain, G. M. Stephan, and G. Maze, "Room-temperature continuous-wave upconversion laser at $455 \mathrm{~nm}$ in a $\mathrm{Tm}^{3+}$ fluorozirconate fiber," Optics Letters, vol. 19, no. 23, pp. 1982-1984, 1994.

[129] R. Paschotta, N. Moore, W. A. Clarkson, A. C. Tropper, D. C. Hanna, and G. Maze, " $230 \mathrm{~mW}$ of blue light from a thuliumdoped upconversion fiber laser," IEEE Journal on Selected Topics in Quantum Electronics, vol. 3, no. 4, pp. 1100-1102, 1997.

[130] G. Qin, S. Huang, Y. Feng, A. Shirakawa, and K.-I. Ueda, "Multiple-wavelength up-conversion laser in $\mathrm{Tm}^{3+}$-doped ZBLAN glass fiber," IEEE Photonics Technology Letters, vol. 17, no. 9, pp. 1818-1820, 2005.

[131] H. Zellmer, P. Riedel, and A. Tunnermann, "Visible upconversion lasers in praseodymium-ytterbium-doped fibers," Applied Physics B, vol. 69, no. 5, pp. 417-421, 1999.

[132] P. Xie and T. R. Gosnell, "Room-temperature upconversion fiber laser tunable in the red, orange, green, and blue spectral regions," Optics Letters, vol. 20, pp. 1014-1016, 1995.

[133] M. Zeller, H. G. Limberger, and T. Lasser, "Tunable $\mathrm{Pr}^{3+}$ $\mathrm{Yb}^{3+}$-doped all-fiber upconversion laser," IEEE Photonics Technology Letters, vol. 15, no. 2, pp. 194-196, 2003.
[134] T. Sandrock, H. Scheife, E. Heumann, and G. Huber, "Highpower continuous-wave upconversion fiber laser at room temperature," Optics Letters, vol. 22, no. 11, pp. 808-810, 1997.

[135] D. S. Funk and J. G. Eden, "Laser diode-pumped holmiumdoped fluorozirconate glass fiber laser in the green $(\lambda \sim$ 544-549 nm): power conversion efficiency, pump acceptance bandwidth, and excited-state kinetics," IEEE Journal of Quantum Electronics, vol. 37, no. 8, pp. 980-992, 2001.

[136] D. S. Funk, J. W. Carlson, and J. G. Eden, "Ultraviolet $(381 \mathrm{~nm})$, room temperature laser in neodymium-doped fluorozirconate fibre," Electronics Letters, vol. 30, no. 22, pp. 1859-1860, 1994.

[137] D. S. Funk, J. W. Carlson, and J. G. Eden, "Room-temperature fluorozirconate glass fiber laser in the violet (412 nm)," Optics Letters, vol. 20, pp. 1474-1476, 1995.

[138] T. J. Whitley, C. A. Millar, R. Wyatt, M. C. Brierley, and D. Szebesta, "Upconversion pumped green lasing in erbium doped fluorozirconate fibre," Electronics Letters, vol. 27, no. 20, pp. 1785-1786, 1991.

[139] J. F. Massicott, M. C. Brierley, R. Wyatt, S. T. Davey, and D. Szebesta, "Low threshold, diode pumped operation of a green, $\mathrm{Er}^{3+}$ doped fluoride fibre laser," Electronics Letters, vol. 29, no. 24, pp. 2119-2120, 1993.

[140] D. Piehler and D. Craven, " $11.7 \mathrm{~mW}$ green InGaAs-laserpumped erbium fibre laser," Electronics Letters, vol. 30, no. 21, pp. 1759-1761, 1994.

[141] Y. Chen, D. Meichenin, and F. Auzel, "Room-temperature photon avalanche up-conversion in Er-doped fluoride glass and fibre pumped at $700 \mathrm{~nm}$," Journal of Physics: Condensed Matter, vol. 7, no. 17, pp. 3363-3370, 1995.

[142] A. Saissy, B. Dussardier, G. Maze, G. Monnom, and S. A. Wade, "Blue upconversion emission in $\mathrm{Er}^{3+}$-doped fluoride fiber," Optical Fiber Technology, vol. 2, no. 3, pp. 249-252, 1996.

[143] C. L. Pope, B. R. Reddy, and S. K. Nash-Stevenson, "Efficient violet upconversion signal from a fluoride fiber doped with erbium," Optics Letters, vol. 22, no. 5, pp. 295-297, 1997.

[144] S. R. Bullock, B. R. Reddy, P. Venkateswarlu, S. K. NashStevenson, and J. C. Fajardo, "Energy upconversion and spectroscopic studies of ZBLAN:Er ${ }^{3+}$," Optical and Quantum Electronics, vol. 29, no. 11, pp. 83-92, 1997.

[145] J. Y. Allain, M. Monerie, and H. Poignant, "Blue upconversion fluorozirconate fibre laser," Electronics Letters, vol. 26, no. 3, pp. 166-168, 1990.

[146] S. G. Grubb, K. W. Bennett, R. S. Cannon, and W. F. Humer, "CW room-temperature blue upconversion fibre laser," Electronics Letters, vol. 28, no. 13, pp. 1243-1244, 1992.

[147] S. Sanders, R. G. Waarts, D. G. Mehuys, and D. F. Welch, "Laser diode pumped $106 \mathrm{~mW}$ blue upconversion fiber laser," Applied Physics Letters, vol. 67, pp. 1815-1817, 1995.

[148] H. Zellmer, S. Buteau, A. Tunnermann, and H. Welling, "All fibre laser system with $0.1 \mathrm{~W}$ output power in blue spectral range," Electronics Letters, vol. 33, no. 16, pp. 1383-1384, 1997.

[149] P. Laperle, A. Chandonnet, and R. Vallee, "Photoinduced absorption in thulium-doped ZBLAN fibers," Optics Letters, vol. 20, no. 24, pp. 2484-2486, 1995.

[150] I. J. Booth, J.-L. Archambault, and B. F. Ventrudo, "Photodegradation of near-infrared-pumped $\mathrm{Tm}^{3+}$-doped ZBLAN fiber upconversion lasers," Optics Letters, vol. 21, no. 5, pp. 348-350, 1996. 
[151] P. Laperle, A. Chandonnet, and R. Vallee, "Photobleaching of thulium-doped ZBLAN fibers with visible light," Optics Letters, vol. 22, no. 3, pp. 178-180, 1997.

[152] G. Qin, S. Huang, Y. Feng, A. Shirakawa, M. Musha, and K.-I. Ueda, "Photodegradation and photocuring in the operation of a blue upconversion fiber laser," Journal of Applied Physics, vol. 97, no. 12, pp. 1-3, 2005.

[153] I. J. Booth, C. J. Mackechnie, and B. F. Ventrudo, "Operation of diode laser pumped $\mathrm{Tm}^{3+}$ ZBLAN upconversion fiber laser at $482 \mathrm{~nm}$," IEEE Journal of Quantum Electronics, vol. 32, no. 1, pp. 118-123, 1996.

[154] S. Guy, D. P. Shepherd, M. F. Joubert, B. Jacquier, and H. Poignant, "Blue avalanche upconversion in Tm:ZBLAN fiber," Journal of the Optical Society of America B, vol. 14, no. 4, pp. 926-934, 1997.

[155] G. Tohmon, H. Sato, J. Ohya, and T. Uno, "Thulium:ZBLAN blue fiber laser pumped by two wavelengths," Applied Optics, vol. 36, no. 15, pp. 3381-3386, 1997.

[156] E. B. Mejia, A. N. Starodumov, and Yu. O. Barmenkov, "Blue and infrared up-conversion in $\mathrm{Tm}^{3+}$-doped fluorozirconate fiber pumped at 1.06, 1.117, and $1.18 \mu \mathrm{m}, "$ Applied Physics Letters, vol. 74, no. 11, pp. 1540-1542, 1999.

[157] F. Duclos and P. Urquhart, "Thulium-doped ZBLAN blue upconversion fiber laser: theory," Journal of the Optical Society of America B, vol. 12, no. 4, pp. 709-717, 1995.

[158] R. Paschotta, P. R. Barber, A. C. Tropper, and D. C. Hanna, "Characterization and modeling of thulium:ZBLAN blue upconversion fiber lasers," Journal of the Optical Society of America B, vol. 14, no. 5, pp. 1213-1218, 1997.

[159] G. Qin, S. Huang, Y. Feng, A. Shirakawa, M. Musha, and K.-I. Ueda, "Power scaling of $\mathrm{Tm}^{3+}$ doped ZBLAN blue upconversion fiber lasers: modeling and experiments," Applied Physics B, vol. 82, no. 1, pp. 65-70, 2006.

[160] W. Tian and B. R. Reddy, "Ultraviolet upconversion in thulium-doped fluorozirconate fiber observed under twocolor excitation," Optics Letters, vol. 26, no. 20, pp. 15801582, 2001.

[161] J. Y. Allain, M. Monerie, and H. Poignant, "Tunable CW lasing around 610, 635, 695, 715, 885 and $910 \mathrm{~nm}$ in praseodymium-doped fluorozirconate fibre," Electronics Letters, vol. 27, no. 2, pp. 189-191, 1991.

[162] J. Y. Allain, M. Monerie, and H. Poignant, "Red upconversion $\mathrm{Yb}$-sensitised $\operatorname{Pr}$ fluoride fibre laser pumped in $0.8 \mu \mathrm{m}$ region," Electronics Letters, vol. 27, no. 13, pp. 1156-1157, 1991.

[163] R. G. Smart, J. N. Carter, A. C. Tropper, et al., "CW room temperature operation of praseodymium-doped fluorozirconate glass fibre lasers in the blue-green, green and red spectral regions," Optics Communications, vol. 86, no. 3-4, pp. 333-340, 1991.

[164] R. G. Smart, D. C. Hanna, A. C. Tropper, S. T. Davey, S. F. Carter, and D. Szebesta, "CW room temperature upconversion lasing at blue, green and red wavelengths in infrared-pumped $\mathrm{Pr}^{3+}$-doped fluoride fibre," Electronics Letters, vol. 27, no. 14, pp. 1307-1309, 1991.

[165] Y. Zhao and S. Poole, "Efficient blue $\mathrm{Pr}^{3+}$-doped fluoride fibre upconversion laser," Electronics Letters, vol. 30, no. 12, pp. 967-968, 1994.

[166] D. M. Baney, G. Rankin, and K.-W. Chang, "Blue $\mathrm{Pr}^{3+}$-doped ZBLAN fiber upconversion laser," Optics Letters, vol. 21, no. 17, pp. 1372-1374, 1996.
[167] A. C. Tropper, J. N. Carter, R. D. T. Lauder, D. C. Hanna, S. T. Davey, and D. Szebesta, "Analysis of blue and red laser performance of the infrared-pumped praseodymium-doped fluoride fiber laser," Journal of the Optical Society of America $B$, vol. 11, pp. 886-893, 1994.

[168] P. Peterson and M. P. Sharma, "Modelling of threshold and extraction efficiency in $\operatorname{Pr}^{3+}$ ZBLAN upconversion fibre lasers using two-photon pumping," Optical and Quantum Electronics, vol. 30, no. 3, pp. 161-173, 1998.

[169] H. M. Pask, A. C. Tropper, and D. C. Hanna, "A $\mathrm{Pr}^{3+}$-doped ZBLAN fibre upconversion laser pumped by an $\mathrm{Yb}^{3+}$-doped silica fibre laser," Optics Communications, vol. 134, no. 1-6, pp. 139-144, 1997.

[170] D. M. Baney, L. Yang, J. Ratcliff, and K. W. Chang, "Red and orange $\mathrm{Pr}^{3+} / \mathrm{Yb}^{3+}$ doped ZBLAN fibre upconversion lasers," Electronics Letters, vol. 31, no. 21, pp. 1842-1843, 1995.

[171] D. M. Baney, G. Rankin, and K. W. Chang, "Simultaneous blue and green upconversion lasing in a laser-diode-pumped $\mathrm{Pr}^{3+} / \mathrm{Yb}^{3+}$ doped fluoride fiber laser," Applied Physics Letters, vol. 69, no. 12, pp. 1662-1664, 1996.

[172] D. M. Costantini, H. G. Limberger, T. Lasser, et al., "Actively mode-locked visible upconversion fiber laser," Optics Letters, vol. 25, no. 19, pp. 1445-1447, 2000.

[173] T. P. Baraniecki, R. Caspary, and W. Kowalsky, "All-fiber red fiber laser in ring configuration," Applied Physics B, vol. 83, no. 1, pp. 17-20, 2006.

[174] S. C. Goh, R. Pattie, C. Byrne, and D. Coulson, "Blue and red laser action in $\mathrm{Nd}^{3+}: \mathrm{Pr}^{3+}$ co-doped fluorozirconate glass," Applied Physics Letters, vol. 67, pp. 768-770, 1995.

[175] J. Y. Allain, M. Monerie, and H. Poignant, "Room temperature CW tunable green upconversion holmium fibre laser," Electronics Letters, vol. 26, no. 4, pp. 261-263, 1990.

[176] D. S. Funk, J. G. Eden, J. S. Osinski, and B. Lu, "Green, holmium-doped upconversion fibre laser pumped by red semiconductor laser," Electronics Letters, vol. 33, no. 23, pp. 1958-1960, 1997.

[177] D. S. Funk, S. B. Stevens, and J. G. Eden, "Excitation spectra of the green Ho: fluorozirconate glass fiber laser," IEEE Photonics Technology Letters, vol. 5, no. 2, pp. 154-157, 1993.

[178] D. S. Funk, S. B. Stevens, S. S. Wu, and J. G. Eden, “Tuning, temporal, and spectral characteristics of the green $(\lambda \sim$ $549 \mathrm{~nm}$ ), holmium-doped fluorozirconate glass fiber laser," IEEE Journal of Quantum Electronics, vol. 32, no. 4, pp. 638645, 1996.

[179] R. R. Alfano and S. L. Shapiro, "Emission in the region 4000 to 7000 via four-photon coupling in glass," Physical Review Letters, vol. 24, no. 11, pp. 584-587, 1970.

[180] N. G. Bondarenko, I. V. Eremina, and V. I. Talanov, "Broadening of spectrum in self-focusing of light in crystals," JETP Letters, vol. 12, pp. 85-87, 1970.

[181] C. Lin and R. H. Stolen, "New nanosecond continuum for excited-state spectroscopy," Applied Physics Letters, vol. 28, no. 4, pp. 216-218, 1976.

[182] J. K. Ranka, R. S. Windeler, and A. J. Stentz, "Visible continuum generation in air-silica microstructure optical fibers with anomalous dispersion at $800 \mathrm{~nm}$," Optics Letters, vol. 25, no. 1, pp. 25-27, 2000.

[183] C. L. Hagen, J. W. Walewski, and S. T. Sanders, "Generation of a continuum extending to the midinfrared by pumping ZBLAN fiber with an ultrafast 1550 -nm source," IEEE Photonics Technology Letters, vol. 18, no. 1, pp. 91-93, 2006. 
[184] C. Xia, M. Kumar, O. P. Kulkarni, et al., "Mid-infrared supercontinuum generation to $4.5 \mu \mathrm{m}$ in ZBLAN fluoride fibers by nanosecond diode pumping," Optics Letters, vol. 31, no. 17, pp. 2553-2555, 2006.

[185] C. Xia, M. Kumar, M. -Y. Cheng, et al., "Power scalable mid-infrared supercontinuum generation in ZBLAN fluoride fibers with up to 1.3 watts time-averaged power," Optics Express, vol. 15, no. 3, pp. 865-871, 2007.

[186] M. N. Islam, C. Xia, M. J. Freeman, et al., "Mid-IR super-continuum generation," in Fiber Lasers VI: Technology, Systems, and Applications, vol. 7195 of Proceedings of SPIE, San Jose, Calif, USA, January 2009.

[187] C. Xia, Z. Xu, M. N. Islam, et al., " $10.5 \mathrm{~W}$ timeaveraged power mid-IR supercontinuum generation extending beyond $4 \mu \mathrm{m}$ with direct pulse pattern modulation," IEEE Journal on Selected Topics in Quantum Electronics, vol. 15, no. 2, pp. 422-434, 2009.

[188] G. Qin, X. Yan, C. Kito, et al., "Supercontinuum generation spanning over three octaves from UV to $3.85 \mu \mathrm{m}$ in a fluoride fiber," Optics Letters, vol. 34, no. 13, pp. 2015-2017, 2009.

[189] H. Ebendorff-Heidepriem, T.-C. Foo, R. C. Moore, et al., "Fluoride glass microstructured optical fiber with large mode area and mid-infrared transmission," Optics Letters, vol. 33, no. 23, pp. 2861-2863, 2008.

[190] Z. Chen, A. J. Taylor, and A. Efimov, "Coherent mid-infrared broadband continuum generation in non-uniform ZBLAN fiber taper," Optics Express, vol. 17, no. 7, pp. 5852-5860, 2009.

[191] F. G. Omenetto, N. A. Wolchover, M. R. Wehner, et al., "Spectrally smooth supercontinuum from $350 \mathrm{~nm}$ to $3 \mu \mathrm{m}$ in sub-centimeter lengths of soft-glass photonic crystal fibers," Optics Express, vol. 14, no. 11, pp. 4928-4934, 2006.

[192] J. H. V. Price, T. M. Monro, H. Ebendorff-Heidepriem, et al., "Mid-IR supercontinuum generation from nonsilica microstruetured optical fibers," IEEE Journal on Selected Topics in Quantum Electronics, vol. 13, no. 3, pp. 738-749, 2007.

[193] P. Domachuk, N. A. Wolchover, M. Cronin-Golomb, et al., "Over $4000 \mathrm{~nm}$ bandwidth of Mid-IR supercontinuum generation in sub-centimeter segments of highly nonlinear tellurite PCFs," Optics Express, vol. 16, no. 10, pp. 7161-7168, 2008.

[194] S. D. Jackson, "Direct evidence for laser reabsorption as initial cause for self-pulsing in three-level fibre lasers," Electronics Letters, vol. 38, no. 25, pp. 1640-1642, 2002.

[195] D. C. Brown and H. J. Hoffman, "Thermal, stress, and thermo-optic effects in high average power double-clad silica fiber lasers," IEEE Journal of Quantum Electronics, vol. 37, no. 2, pp. 207-217, 2001.

[196] P. R. Barber, R. Paschotta, A. C. Tropper, and D. C. Hanna, "Infrared-induced photodarkening in Tm-doped fluoride fibers," Optics Letters, vol. 20, pp. 2195-2197, 1995.

[197] D. Grobnic, S. J. Mihailov, and C. W. Smelser, "Femtosecond IR laser inscription of Bragg gratings in single- and multimode fluoride fibers," IEEE Photonics Technology Letters, vol. 18, no. 24, pp. 2686-2688, 2006.

[198] M. Bernier, D. Faucher, R. Vallee, et al., "Bragg gratings photoinduced in ZBLAN fibers by femtosecond pulses at 800 nm," Optics Letters, vol. 32, no. 5, pp. 454-456, 2007.

[199] T. Y. Fan, "Laser beam combining for high-power, highradiance sources," IEEE Journal on Selected Topics in Quantum Electronics, vol. 11, no. 3, pp. 567-577, 2005. 

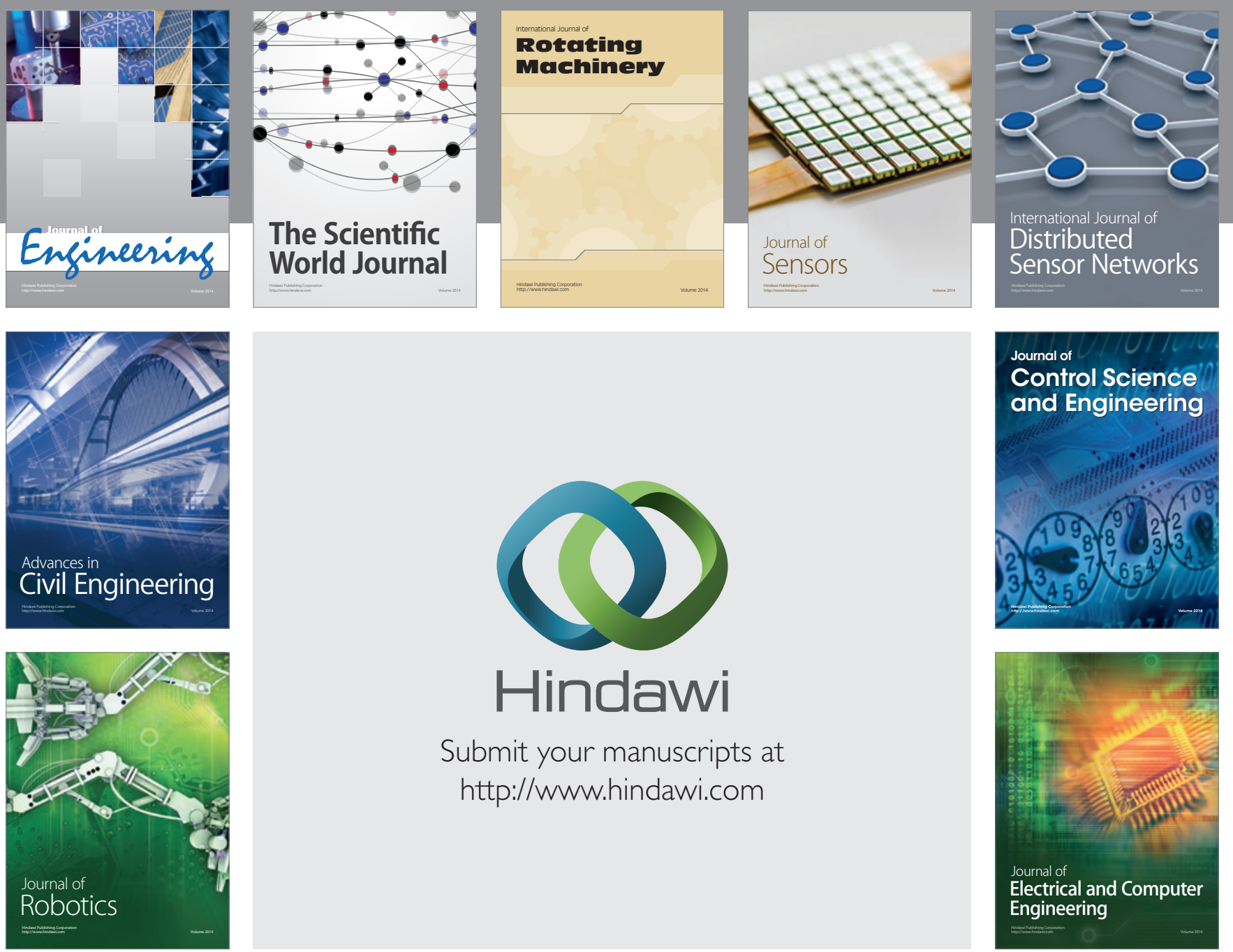

Submit your manuscripts at

http://www.hindawi.com
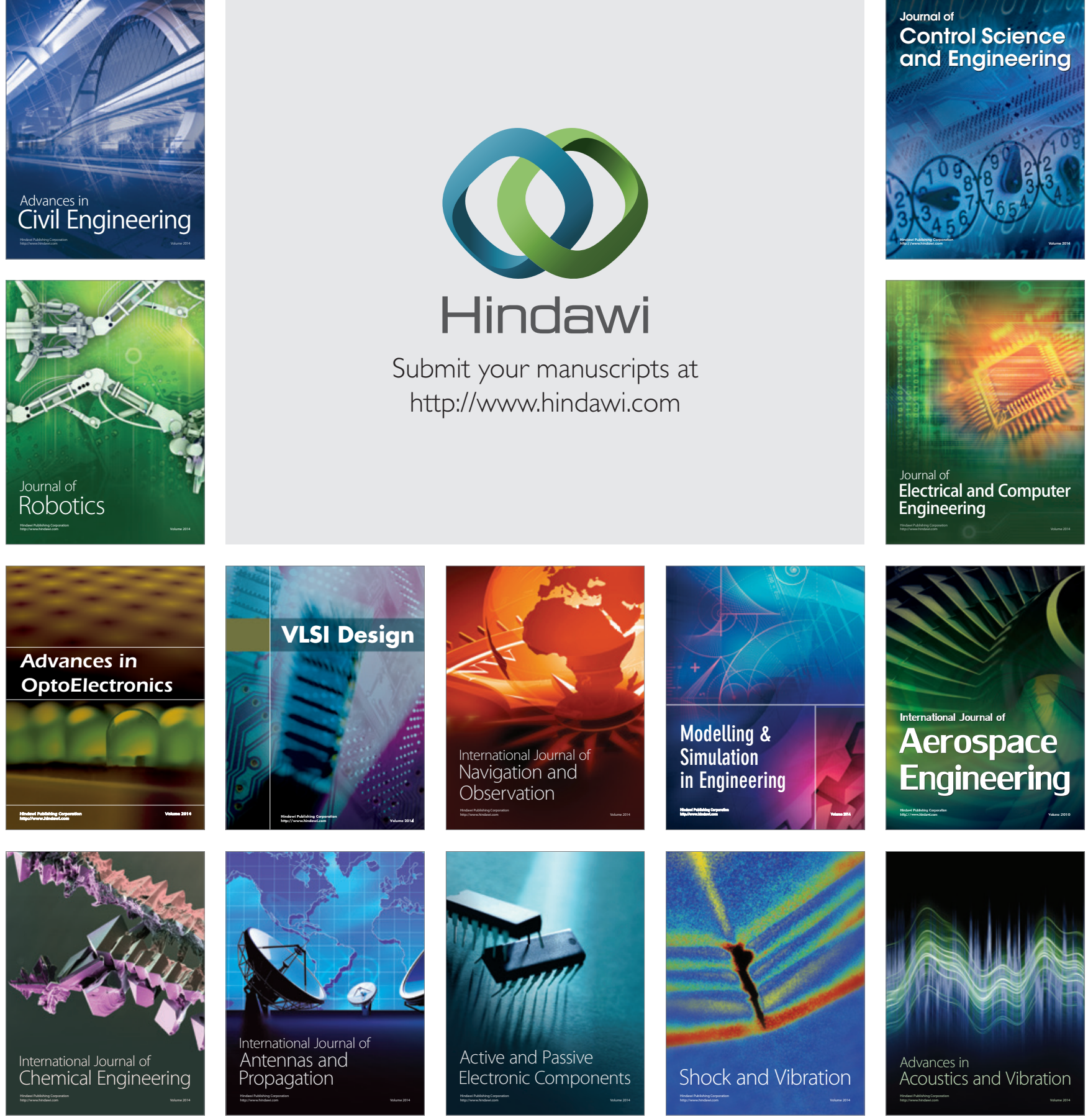